\title{
Simple and fast prediction of train-induced track forces, ground and building vibrations
}

\author{
Lutz Auersch ${ }^{1}$ (D)
}

Received: 25 May 2020/Revised: 30 July 2020/Accepted: 6 August 2020/Published online: 6 September 2020

(C) The Author(s) 2020

\begin{abstract}
A simple and fast prediction scheme is presented for train-induced ground and building vibrations. Simple models such as (one-dimensional) transfer matrices are used for the vehicle-track-soil interaction and for the building-soil interaction. The wave propagation through layered soils is approximated by a frequency-dependent homogeneous half-space. The prediction is divided into the parts "emission" (excitation by railway traffic), "transmission" (wave propagation through the soil) and "immission" (transfer into a building). The link between the modules is made by the excitation force between emission and transmission, and by the free-field vibration between transmission and immission. All formula for the simple vehicle-track, soil and building models are given in this article. The behaviour of the models is demonstrated by typical examples, including the mitigation of train vibrations by elastic track elements, the low- and high-frequency cut-offs characteristic for layered soils, and the interacting soil, wall and floor resonances of multi-storey buildings. It is shown that the results of the simple prediction models can well represent the behaviour of the more time-consuming detailed models, the finite-element boundary-element models of the track, the wavenumber integrals for the soil and the three-dimensional finite-element models of the building. In addition, measurement examples are given for each part of the prediction, confirming that the methods provide reasonable results. As the prediction models are fast in calculation, many predictions can be done, for example to assess the environmental effect along a new
\end{abstract}

Lutz Auersch

lutz.auersch-saworski@bam.de

1 Federal Institute of Materials Research and Testing, D-12200 Berlin, Germany railway line. The simple models have the additional advantage that the user needs to know only a minimum of parameters. So, the prediction is fast and user-friendly, but also theoretically and experimentally well-founded.

Keywords Railway-induced vibration - Ground vibration · Layered soil · Building response · Excitation forces · Track and vehicle irregularities

\section{List of symbols}

A Amplitude

$A_{\mathrm{L}} \quad$ Layer amplitude

$A_{\mathrm{H}} \quad$ Half-space amplitude

$A_{\mathrm{S}} \quad$ Soil area under the foundation

$A_{\mathrm{W}} \quad$ Cross-area of the wall

$b \quad$ Track width

$b^{*} \quad$ Normalised track width

$c$ Damping of the soil under the foundation

$C^{\prime} \quad$ Damping matrix

$d_{\mathrm{C}} \quad$ Thickness of the column

$d_{\mathrm{W}} \quad$ Thickness of the wall

$d_{\mathrm{F}} \quad$ Thickness of the floor

$D \quad$ Material damping ratio of track or building material

$E_{\mathrm{C}} \quad$ Elasticity modulus of concrete

$E_{\mathrm{M}} \quad$ Elasticity modulus of masonry

$\boldsymbol{e}_{1}, \boldsymbol{e}_{2} \quad$ Base vectors

EI Bending stiffness

EI Bending stiffness matrix

$f \quad$ Frequency

$f_{0} \quad$ Basic resonance frequency of the building

$f_{1} \quad$ Layer frequency

$f_{\mathrm{C}} \quad$ Resonance frequency of the wall/column

$f_{\mathrm{F}} \quad$ Eigenfrequency of the floor

$F \quad$ Force (point load) 
$F_{\mathrm{S}} \quad$ Force on the soil

$F_{\mathrm{T}} \quad$ Force on the track

$F_{\mathrm{W}} \quad$ Force acting from the floor on the wall

$F^{*} \quad$ Reduced point load

$\boldsymbol{F}_{\mathrm{T}} \quad$ Force vector on the track

$G \quad$ Shear modulus of the soil

$h \quad$ Height of a storey

$h_{1} \quad$ Height of the soil layer

$h_{\mathrm{B}} \quad$ Height of the ballast

$H \quad$ Height of the building

$H_{\mathrm{P}} \quad$ Transfer function for a point load on the soil

$H_{\mathrm{T}} \quad$ Force transfer function of the track

$H_{\mathrm{V}} \quad$ Transfer function of vehicle-track interaction

$k \quad$ Stiffness of the soil under the foundation

$k_{\mathrm{B}} \quad$ Static stiffness of the ballast

$k_{\mathrm{W}} \quad$ Static stiffness of the wall

$K_{\mathrm{T}} \quad$ Dynamic stiffness of the track

$K_{\mathrm{V}} \quad$ Dynamic stiffness of the vehicle

$\boldsymbol{K}^{\prime} \quad$ Stiffness matrix

$\boldsymbol{K}_{\mathrm{TS}}^{\prime} \quad$ Dynamic stiffness matrix of the track and the soil

$L \quad$ Length of the train

$l_{\mathrm{F}} \quad$ Length of the floor

$m_{\mathrm{W}} \quad$ Mass of the wheelset

$m^{\prime} \quad$ Mass per track length

M Mass matrix

$n \quad$ Number of axles, number of storeys

$r \quad$ Distance from the point load

$r^{*} \quad$ Normalised distance

$r_{0}^{*} \quad$ End of near field

$s \quad$ Vehicle and track irregularities

$\boldsymbol{T} \quad$ Transfer matrix

$\boldsymbol{T}_{\mathrm{B}} \quad$ Transfer matrix of the ballast

$\boldsymbol{T}_{\mathrm{E}} \quad$ Transfer matrix of an elastic track element

$\boldsymbol{T}_{\mathrm{F}}, \boldsymbol{T}_{\mathrm{R}}$ Transfer matrix of the (rigid) floor

$\boldsymbol{T}_{\mathrm{M}} \quad$ Transfer matrix of a mass (e.g. the sleeper)

$\boldsymbol{T}_{\mathrm{S}} \quad$ Transfer matrix of the soil (foundation)

$\boldsymbol{T}_{\mathrm{W}} \quad$ Transfer matrix of the wall/column

$u \quad$ Displacement

$u_{0} \quad$ Free-field displacement of the soil

$u_{\mathrm{F}} \quad$ Displacement of the middle of the floor

$u_{\mathrm{R}} \quad$ Displacement of the rail

$u_{\mathrm{S}} \quad$ Displacement of the soil (under the track)

$u_{\mathrm{W}} \quad$ Displacement of the wall/column

$v \quad$ Particle velocity of the ground

$v_{\mathrm{B}} \quad$ Velocity of the longitudinal wave in the ballast

$v_{\mathrm{L}} \quad$ Velocity of the longitudinal wave in the wall/column

$v_{\mathrm{R}} \quad$ Velocity of the Rayleigh wave

$v_{\mathrm{S}} \quad$ Velocity of the shear wave

$v(x) \quad$ Mode shape of the floor

$V \quad$ Amplification factor

$x \quad$ Distance to the middle of the track $y_{j} \quad$ Position of axle $j$ along the track

$\alpha \quad$ Modal displacement factor

$\eta \quad$ Frequency ratio

$\lambda$ Wavelength

$\mu \quad$ Modal mass factor

$v \quad$ Poisson's ratio

$\rho \quad$ Mass density

$\xi \quad$ Wavenumber along the track length

$\omega \quad$ Circular frequency, $2 \pi f$

\section{Introduction}

The railway-induced ground and building vibrations have been extensively analysed by measurements and detailed models. In the German research work [1, 2], the knowledge about railway vibrations had to be condensed in a prediction programme which could be used by experts as well as by non-experts. The challenge was to generate similar results as detailed models do, but with much less computer time and detailing. This is quite contrary to the usual task of programming complex and more complex models. This task is, nevertheless, as difficult, because complex models must be calculated and the results must be understood. Finally, approximating models must be found which are physically meaningful rather than black box approximations. It must be pointed out that the simple prediction methods could not be developed without detailed models, for example three-dimensional finite-element models. The results of many detailed models serve as a guide for finding proper approximations.

At the beginning, railway-induced ground vibrations have been analysed by experiments. A prediction was based on measurements at a different situation and on the experience and the intuition of the engineer how to transfer the results to the new situation. This method can be structured in a prediction software where only certain influencing factors are allowed and can be derived statistically from an experimental database [3-6]. Another purely experimental method uses impact measurements on the site and train measurements on another site to predict the train vibrations at the site [7].

On the other side, theoretical methods have been developed for the wave propagation through the soil and the soil-structure interaction. Basic work has been done in the 1980s and early 1990s by SNCF [8], British Rail Research [9] and BAM [10]. The wave propagation through layered soils can be calculated by wavenumber 
integrals [11-13]. Tracks on the soil can also be solved by wavenumber domain methods $[8,9,14-16]$. Many alternatives for track-soil interaction have been developed. Large three-dimensional finite-element regions are possible with transmitting boundaries [17-19]. The combined finiteelement boundary-element method has been used for the track-soil [20] and the building-soil interaction [21]. Finite-element and boundary-element methods across the track can be combined with the wavenumber method along the track yielding the so-called 2.5-dimensional method [22-26].

All these detailed methods are very time-consuming. If a larger area needs many predictions, so-called scoping predictions have been developed $[27,28]$. They use neural networks $[29,30]$ or other methods of artificial intelligence [31] to represent the results of many time-consuming calculations.

Scoping predictions have also been found for buildings [32], where only the relevant building modes are used in a fast computation. Many simplifications of building vibrations have been used, so far. In [33], the calculations of detailed models have been used to find simple explicit building transfer functions. Simplified building models have been achieved by considering infinitely long buildings $[34,35]$, infinitely high buildings [36] and infinitely high buildings with flexible floors [37]. Simple finite structures composed of columns and floors have been used, in [38] a single column and infinitely large floors, and in [39] multicolumn and multi-floor bay models.
Buildings have been often calculated without the underlying soil or with a very stiff soil $[33,38-42]$. The soft soil, however, yields an amplitude reduction with increasing frequency, modifies the resonance frequencies and mode shapes and provides a strong radiation damping. Without the soil, many resonance peaks appear in the solution which are not present for the building model with the soil. The building-soil interaction should be included in the building analysis even if the propagation through the soil and the response of the building is calculated separately.

In the same way, the track-soil interaction should be included in the excitation analysis even if the propagation through the soil is analysed in the next step [18, 43, 44]. The coupling of the track (the excitation step) and the soil (the propagation step) can be done by the total force on the soil. This way of coupling is used in this article as it has some advantages if mitigation measures at track are analysed, and it represents better the excitation than any displacement quantity. Coupled (substructure) models have also been used for the full three stage prediction, for example [40-42].

A single track-soil model for the emission and transmission has often been used, for example [15, 19, 45]. A single model for all three parts of the prediction, the track, the soil and the building need time-consuming computations and are rarely found [17, 21, 46]. More examples of detailed models can be found in the state-of-the-art articles [47-49]. (a)

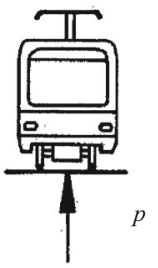

(c)

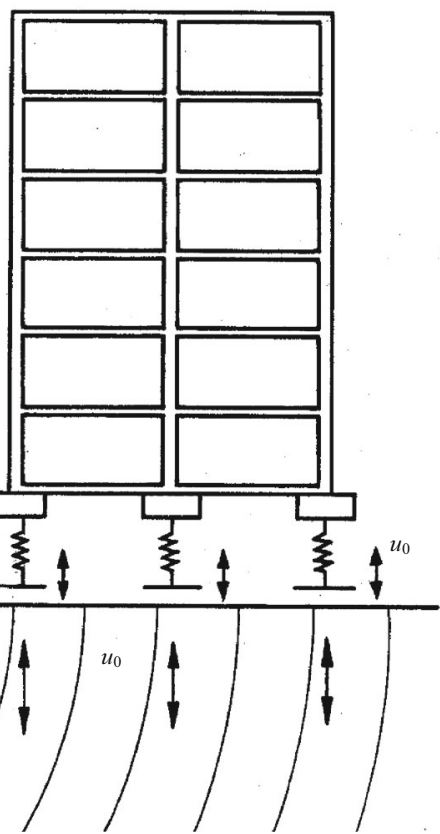

Fig. 1 The prediction of railway-induced vibration and its part $\mathbf{a}$ emission from the train, $\mathbf{b}$ transmission through the soil, and $\mathbf{c}$ immission into the building 
The present article describes a fast prediction of all three parts (Fig. 1), emission (excitation by rail traffic), transmission (propagation through the soil) and immission (response of buildings). Physical models are used for all parts. The track-soil model is calculated by transfer matrices of the rail, rail pad, sleeper, ballast, soil and all possible elastic elements for mitigation. The building model of a column/wall and adjacent floors is also calculated by transfer matrices. The approximating model of the layered half-space is a homogeneous half-space with a frequencydependent wave velocity. These prediction methods are fast in computation, the response follows within a second, but also simple in handling, as only a minimum of parameters is needed as the input. The prediction methods have been derived from several detailed methods, such as the thin-layer method, different finite-element methods, the boundary-element method, wavenumber integrals and wavenumber domain methods for the calculation of tracks. At the same time, many measurements (in 50 buildings, at 40 ground vibration sites and at 30 railway tracks) have been performed which have been used to thoroughly test the prediction methods. This article presents some comparison of the prediction methods with detailed numerical methods and with some measurements which demonstrate that this comprehensive prediction is theoretically wellfounded and of practical value.

This article is organised as follows. Sections 2, 4 and 6 present the complete set of formula for each part of the prediction emission (excitation of railway vibration), transmission (propagation of waves through the soil) and immission (response of the building). Each section with the formula is followed by a section (Sects. 3, 5, 7) including some example results, the comparison with detailed numerical models and with measurements which shows the good theoretical agreement and the practical relevance of the prediction methods. The article ends with the conclusions.

\section{Emission: excitation forces from vehicle-track interaction}

The excitation forces are calculated from the vehicle and track irregularities and the vehicle-track interaction. By that, the excitation forces can be predicted, but also the mitigation effect of any mitigation measure at track (such as rail pads, sleeper pads and ballast mats) can be determined.

\subsection{Vehicle and track irregularities}

The main causes of train-induced ground vibrations are irregularities of the vehicle and the track. The amplitudes $s$ of the different irregularities depend on the condition of the vehicle and track, but the following general rules for the third-of-octave band spectra have been found $[2,50]$ :

track alignment:

$s(\lambda) \sim \lambda^{1.5-2}, \quad \lambda>1.2 \mathrm{~m}, \quad s(\lambda=2 \mathrm{~m})=0.017-0.17 \mathrm{~mm} ;$

wheel out-of-roundness:

$s(\lambda) \sim \lambda^{0.5-1}, \quad 0.3 \mathrm{~m}<\lambda<3 \mathrm{~m}, \quad s(\lambda=1 \mathrm{~m})=0.005-0.015 \mathrm{~mm} ;$ wheel roughness:

$s(\lambda) \sim \lambda^{0.5}, \quad \lambda<0.3 \mathrm{~m}, \quad s(\lambda=0.25 \mathrm{~m})=0.002-0.007 \mathrm{~mm}$ rail roughness:

$s(\lambda) \sim \lambda^{0.5-1}, \quad \lambda<0.5 \mathrm{~m}, \quad s(\lambda=0.2 \mathrm{~m})=0.001-0.005 \mathrm{~mm}$.

The irregularities are given as a function of the wavelength $\lambda$, but this can also be translated to a function of the frequency $f$ depending on the train speed $v_{\mathrm{T}}$ according to $f=v_{\mathrm{T}} / \lambda$. The track yields long-wavelength (low frequency) alignment irregularities and short-wavelength (high-frequency) roughness irregularities. The wheel irregularities include the out-of-roundness at mid-frequencies (the first and second out-of-roundnesses are single peaks) and the roughness for higher frequencies (short wavelengths). The irregularities $s$ increase with the wavelength $\lambda$, strongest for the track alignment, and this means a decrease with frequency $f, s(\lambda) \sim \lambda^{q}$ means $s(f) \sim f^{-q}$.

The spectrum of the combined track and vehicle irregularities is the starting point of a complete prediction of railway vibrations. Within the above limits, simplified spectra for good, medium and bad vehicle and track conditions are provided [2].

\subsection{Simple vehicle and multi-beam-on-Winkler- support track models}

The dynamic stiffness $K_{\mathrm{V}}$ of the vehicle can be approximated by the inertia of the wheelset:

$K_{\mathrm{V}}(\omega)=-m_{\mathrm{W}} \omega^{2}$,

where $m_{\mathrm{W}}$ is the mass of the wheelset and $\omega=2 \pi f$ is the circular frequency of excitation. The minor effects of the low-frequency rigid and elastic vibrations of the carbody and bogies have been proved in [51].

Many track systems have been calculated by the combined finite-element boundary-element method [20], and the results have been used to derive a faster multi-beam-onWinkler-support track model (Fig. 2). This track model consists of $n$ beams which represent the rails and track slabs and which are described by the bending stiffness $E I_{j}$ 


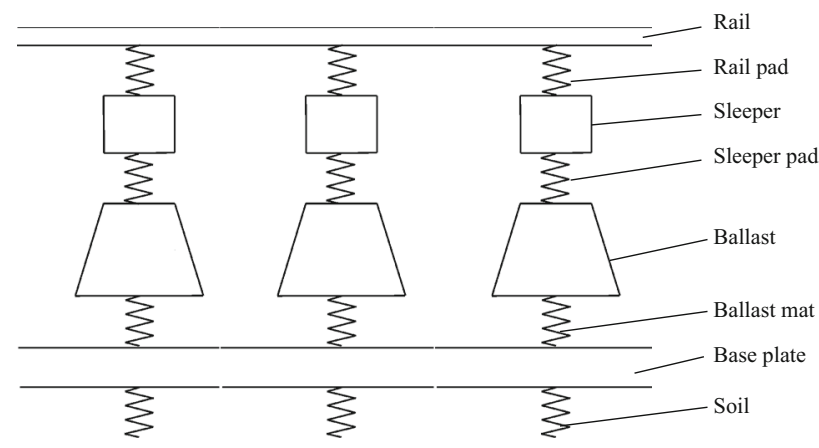

Fig. 2 Model of the track: multi-beam on support or multi-beam on soil system

and the mass per length $m_{j}^{\prime}$, and by support elements representing rail pads, sleepers, the ballast and any isolation element. The multi-beam system fulfils the following set of differential equations for the displacements $\boldsymbol{u}$ and the load $\boldsymbol{F}_{\mathrm{T}}$

$\boldsymbol{E} \boldsymbol{I} \frac{\partial^{4} \boldsymbol{u}}{\partial y^{4}}+\boldsymbol{M} \frac{\partial^{2} \boldsymbol{u}}{\partial t^{2}}+\boldsymbol{C}^{\prime} \frac{\partial \boldsymbol{u}}{\partial t}+\boldsymbol{K}^{\prime} \boldsymbol{u}=\boldsymbol{F}_{\mathrm{T}}^{\prime}$.

This equation transformed into the frequencywavenumber domain reads

$$
\begin{aligned}
\left(\xi^{4} \boldsymbol{E I}-\omega^{2} \boldsymbol{M}+i \omega \boldsymbol{C}^{\prime}+\boldsymbol{K}^{\prime}\right) \boldsymbol{u} & =\left(\xi^{4} \boldsymbol{E I}+\boldsymbol{K}_{\mathrm{TS}}^{\prime}(\omega)\right) \boldsymbol{u} \\
& =\boldsymbol{F}_{\mathrm{T}}^{\prime}(\omega),
\end{aligned}
$$

where $\boldsymbol{K}_{\mathrm{TS}}^{\prime}(\omega)$ is the dynamic track-soil stiffness matrix which is calculated by transfer matrices for each support element.

Transfer matrices $\boldsymbol{T}$ relate the state ( $F$ force and $u$ displacement) of the bottom and the top of each support element as

$\left[\begin{array}{l}F_{1} \\ u_{1}\end{array}\right]=\left[\begin{array}{ll}T_{11} & T_{12} \\ T_{21} & T_{22}\end{array}\right]\left[\begin{array}{l}F_{2} \\ u_{2}\end{array}\right]$.

The forces point to the element and $F_{1}$ and $u_{1}$ have the same direction. An elastic spring element (stiffness $k$, for example a rail pad, a sleeper pad or a ballast mat) yields

$\boldsymbol{T}_{\mathrm{E}}=\left[\begin{array}{cc}1 & 0 \\ 1 / k & 1\end{array}\right]$.

The spring-damper element for the Winkler soil reads similarly

$\boldsymbol{T}_{\mathrm{S}}=\left[\begin{array}{cc}1 & 0 \\ 1 /(k+c i \omega) & 1\end{array}\right]$.

A mass element (mass $m$, for example the sleeper) would yield
$\boldsymbol{T}_{\mathrm{M}}=\left[\begin{array}{cc}1 & -m \omega^{2} \\ 0 & 1\end{array}\right]$

The transfer matrix of a column, which is used for the ballast, reads

$\boldsymbol{T}_{\mathrm{C}}=\left[\begin{array}{cc}\cos a & -\sin a \cdot k_{\mathrm{B}} a \\ \sin a / k_{\mathrm{B}} a & \cos a\end{array}\right]$,

with the static stiffness $k_{\mathrm{B}}=E_{\mathrm{B}} A_{\mathrm{B}} / h_{\mathrm{B}}$, the area $A_{\mathrm{B}}$, the height $h_{\mathrm{B}}$, the longitudinal wave velocity $v_{\mathrm{B}}$ of the ballast and $a=\omega h_{\mathrm{B}} / v_{\mathrm{B}}$ a non-dimensional wave parameter. This transfer matrix allows wave propagation through the ballast at high frequencies.

The transfer function of a support section is achieved by multiplying the transfer functions of all support elements (for example rail pad, sleeper, ballast and soil, see Fig. 2) as

$\boldsymbol{T}=\boldsymbol{T}_{\mathrm{E}} \boldsymbol{T}_{\mathrm{M}} \boldsymbol{T}_{\mathrm{B}} \boldsymbol{T}_{\mathrm{S}}$.

The transfer matrix $\boldsymbol{T}$ is transformed to the stiffness matrix $\boldsymbol{K}$ as

$$
\begin{aligned}
{\left[\begin{array}{c}
F_{1} \\
-F_{2}
\end{array}\right] } & =\frac{1}{T_{21}}\left[\begin{array}{cc}
T_{11} & -\operatorname{det} \boldsymbol{T} \\
-1 & T_{22}
\end{array}\right]\left[\begin{array}{l}
u_{1} \\
u_{2}
\end{array}\right] \\
& =\frac{1}{T_{21}}\left[\begin{array}{ll}
T_{11} & -1 \\
-1 & T_{22}
\end{array}\right]\left[\begin{array}{l}
u_{1} \\
u_{2}
\end{array}\right]=\boldsymbol{K} \boldsymbol{u},
\end{aligned}
$$

where $\operatorname{det} \boldsymbol{T}=1$ for passive systems, and the sign definition is different for $F_{2}$; and the stiffness matrix $\boldsymbol{K}$ is added to the system Eq. (4).

A strong simplification is a Winkler soil where the load and displacement are proportional at every point of the soil surface. It has been found that an acceptable approximation $F_{\mathrm{S}} / u_{\mathrm{S}}=k_{\mathrm{S}}+c_{\mathrm{S}} i \omega$ can be established which can be used for the dynamic compliance of the track-soil system under the axle load.

The dynamic track stiffness $K_{\mathrm{T}}(\omega)$ at the wheel-rail contact can be calculated as the wavenumber integral

$\frac{1}{K_{T}(\omega)}=\frac{u_{\mathrm{R}}}{F_{T}}(\omega)=\frac{1}{2} \int_{-\infty}^{\infty} \boldsymbol{e}_{1}^{\mathrm{T}}\left(\xi^{4} \boldsymbol{E} \boldsymbol{I}+\boldsymbol{K}_{\mathrm{TS}}^{\prime}(\omega)\right)^{-1} \boldsymbol{e}_{1} \mathrm{~d} \xi$,

where the base vectors $\boldsymbol{e}_{1}$ indicate the components of the matrix, $\quad\left(\xi^{4} \boldsymbol{E} \boldsymbol{I}+\boldsymbol{K}_{\mathrm{TS}}^{\prime}(\omega)\right)^{-1}$ the compliance in wavenumber domain according to Eq. (4), and the spatial constant $F_{\mathrm{T}}$ is the wavenumber transform of the point load. The force transfer from top to bottom of the track follows as 


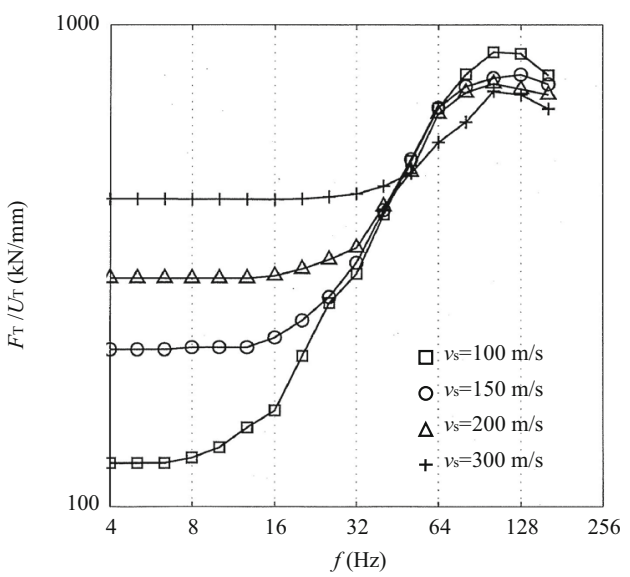

(a)

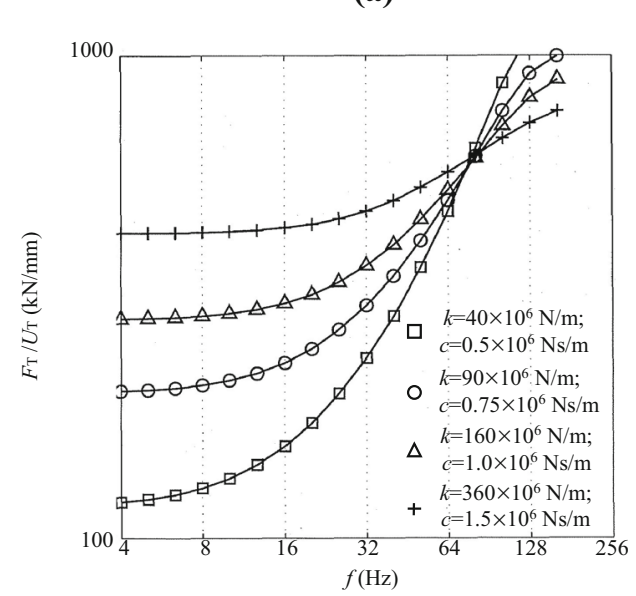

(c)

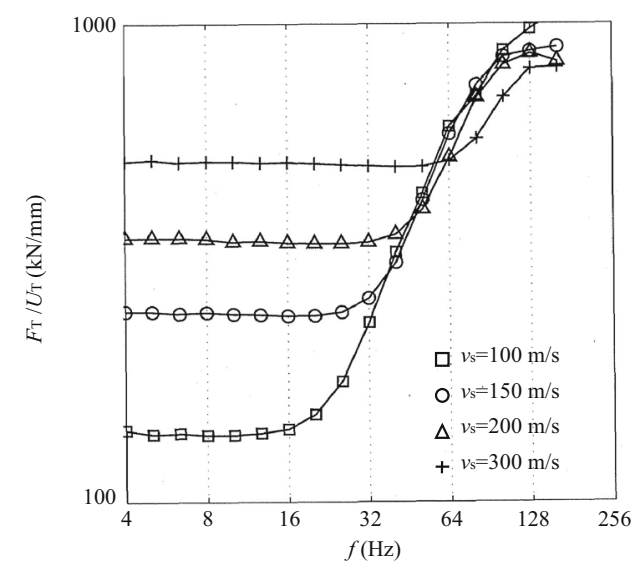

(b)

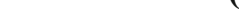


Table 1 Parameters of the emission part (per one sleeper)

\begin{tabular}{lll}
\hline Wheelset mass & $m_{\mathrm{W}}$ & $1500 \mathrm{~kg}(1000-3000 \mathrm{~kg})$ \\
Rail stiffness & $E I_{\mathrm{R}}$ & $12.8 \times 10^{6} \mathrm{Nm}^{2}$ \\
Rail mass & $m^{\prime}{ }_{\mathrm{R}}$ & $2 \times 60 \mathrm{~kg} / \mathrm{m}$ \\
Rail pad stiffness & $k_{\mathrm{R}}$ & $300(20-300) \times 10^{6} \mathrm{~N} / \mathrm{m}$ \\
Sleeper mass & $m_{\mathrm{S}}$ & $340 \mathrm{~kg}$ \\
Sleeper distance & $d$ & $0.6 \mathrm{~m}$ \\
Sleeper pad stiffness & $k_{\mathrm{S}}$ & $\left(10-160 \times 10^{6} \mathrm{~N} / \mathrm{m}\right)$ \\
Ballast height & $h_{\mathrm{B}}$ & $0.3 \mathrm{~m}$ \\
Ballast longitudinal velocity & $v_{\mathrm{B}}$ & $600(200-600) \mathrm{m} / \mathrm{s}$ \\
Ballast area & $A_{\mathrm{B}}$ & $1.1 \mathrm{~m}^{2}$ \\
Soil area & $A_{\mathrm{S}}$ & $1.6 \mathrm{~m}^{2}$ \\
Shear wave velocity of the soil & $v_{\mathrm{S}}$ & $300(100-500) \mathrm{m} / \mathrm{s}$ \\
Soil foundation stiffness & $k$ & $(40-360) \times 10^{6} \mathrm{~N} / \mathrm{m}$ \\
Soil foundation damping & $c$ & $(0.5-1.5) \times 10^{6} \mathrm{Ns} / \mathrm{m}$ \\
Material damping ballast and soil & $D_{\mathrm{S}}$ & 0.025 \\
Material damping of elastic elements & $D$ & 0.1
\end{tabular}

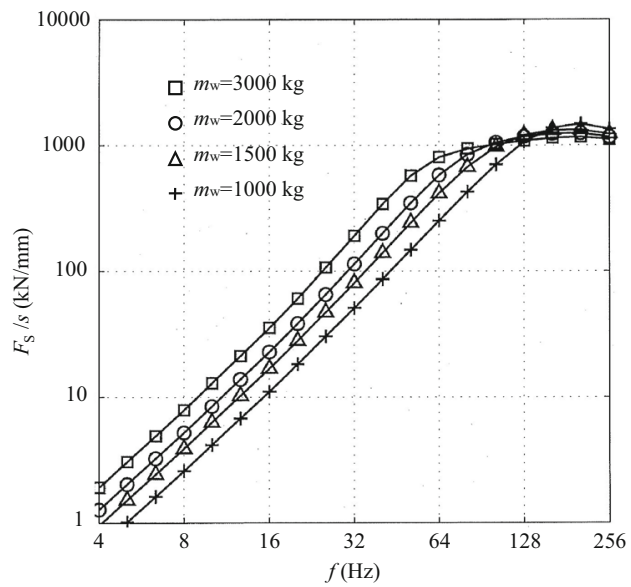

(a)

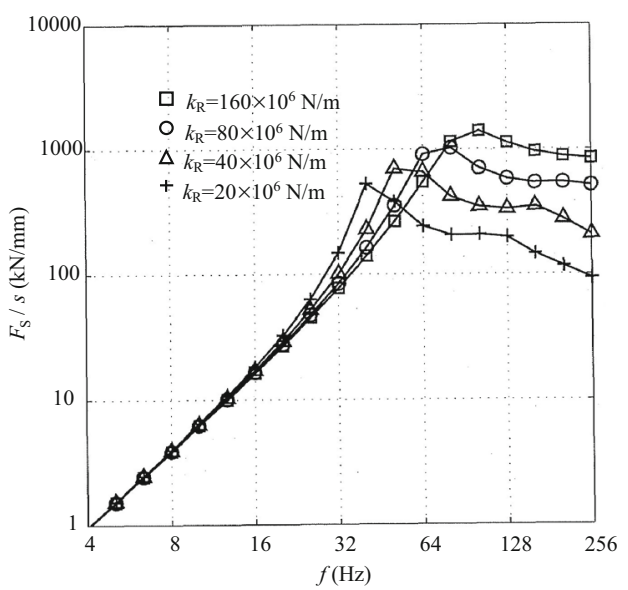

(c) approximation. All results are in the range of $10^{8}-10^{9}$, and the stiffness increases from the low static to the higher dynamic values. The agreement between the approximate and the exact calculations is quite good and well acceptable for the prediction.

Next, the most important vehicle-track-soil transfer function $F_{\mathrm{S}} / s(\omega)=H_{\mathrm{T}}(\omega) H_{\mathrm{V}}(\omega)$ is presented for some vehicle and track parameters (Table 1). The vehicle-tracksoil transfer function is strongly influenced by the unsprung mass of the vehicle, the wheelset mass (Fig. 4a). The dynamic axle-loads are proportional to the wheelset mass for frequencies up to $60 \mathrm{~Hz}$ or even higher. For this frequency range, the transfer function increases with $F_{\mathrm{S}} /$ $s \sim \omega^{2}$. The higher frequency range is determined by the stiffness of the track and the soil which is demonstrated by the variation of the ballast stiffness (the longitudinal wave velocity of the ballast) in Fig. 4b. The stiffer ballast results in a higher vehicle-track resonance frequency up to

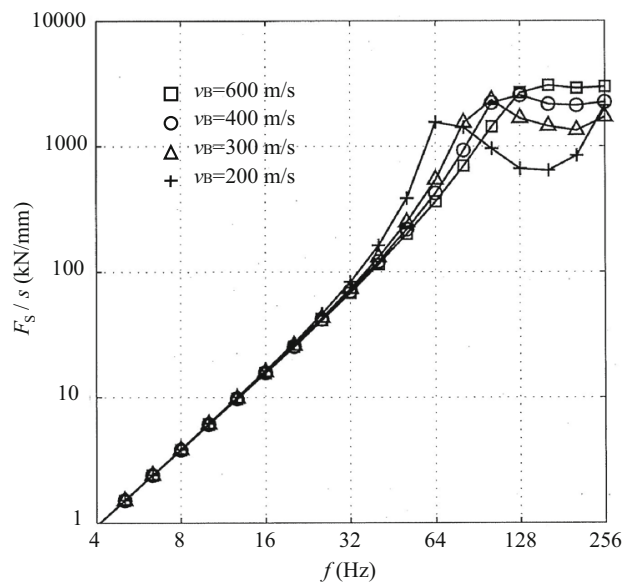

(b)

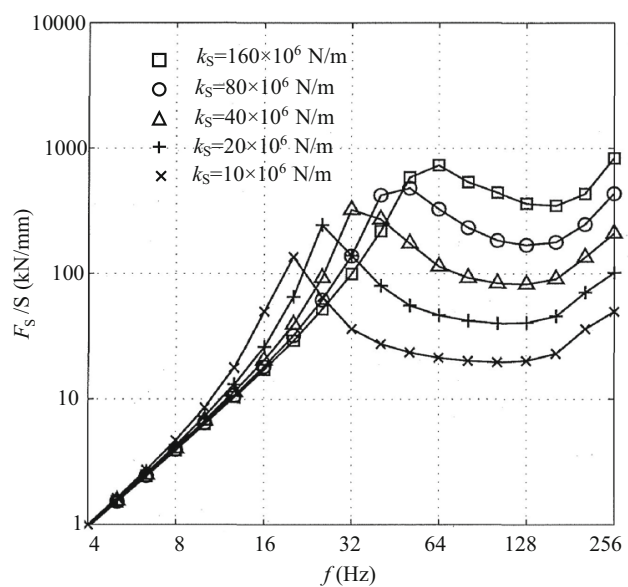

(d)

Fig. 4 Transfer function $F_{\mathrm{S}} / s$ between the irregularities $s$ and the force $F_{\mathrm{S}}$ on the soil: a for different wheelset masses (rail pad $k_{\mathrm{R}}=300 \times 10^{6} \mathrm{~N} / \mathrm{m}$, ballast $v_{\mathrm{B}}=400 \mathrm{~m} / \mathrm{s}$ and soil $\left.v_{\mathrm{S}}=200 \mathrm{~m} / \mathrm{s}\right) ; \mathbf{b}$ for different ballast (rail pad $k_{\mathrm{R}}=\infty$ and soil $\left.v_{\mathrm{S}}=500 \mathrm{~m} / \mathrm{s}\right) ; \mathbf{c}$ for different rail pads (ballast $v_{\mathrm{B}}=600 \mathrm{~m} / \mathrm{s}$ and soil $v_{\mathrm{S}}=300 \mathrm{~m} / \mathrm{s}$ ); $\mathbf{d}$ for different sleeper pads (rail pad $k_{\mathrm{R}}=300 \times 10^{6} \mathrm{~N} / \mathrm{m}$, ballast $v_{\mathrm{B}}=600 \mathrm{~m} / \mathrm{s}$ and soil $v_{\mathrm{S}}=300 \mathrm{~m} / \mathrm{s}$ ) 


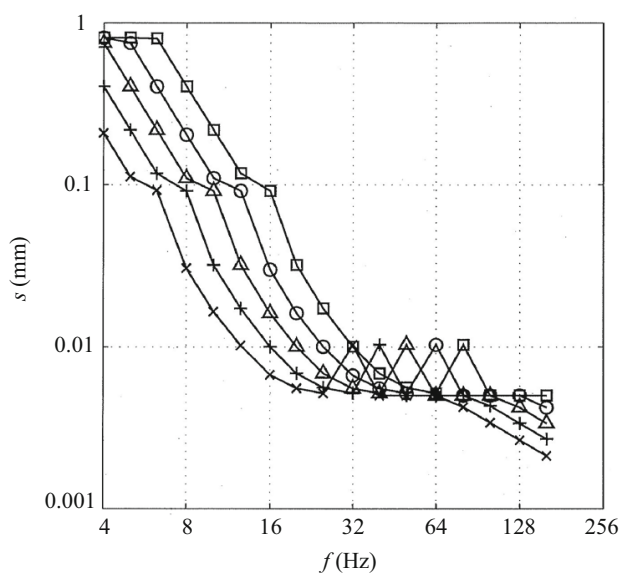

(a)

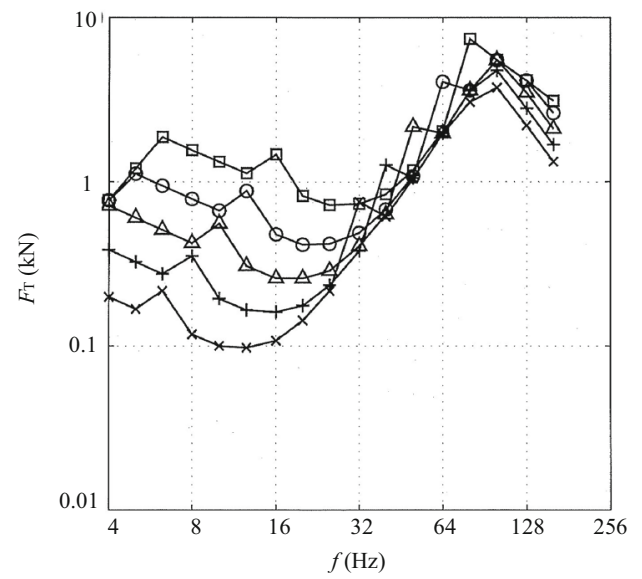

(b)

$\square V_{\mathrm{T}}=160 \mathrm{~km} / \mathrm{h} \quad \circ V_{\mathrm{T}}=125 \mathrm{~km} / \mathrm{h} \Delta V_{\mathrm{T}}=100 \mathrm{~km} / \mathrm{h} \quad+V_{\mathrm{T}}=80 \mathrm{~km} / \mathrm{h} \quad \times \quad V_{\mathrm{T}}=64 \mathrm{~km} / \mathrm{h}$

Fig. 5 Vehicle-track interaction for different train speeds: a wheel and track irregularities $s$ and $\mathbf{b}$ force on the track $F_{\mathrm{T}}$

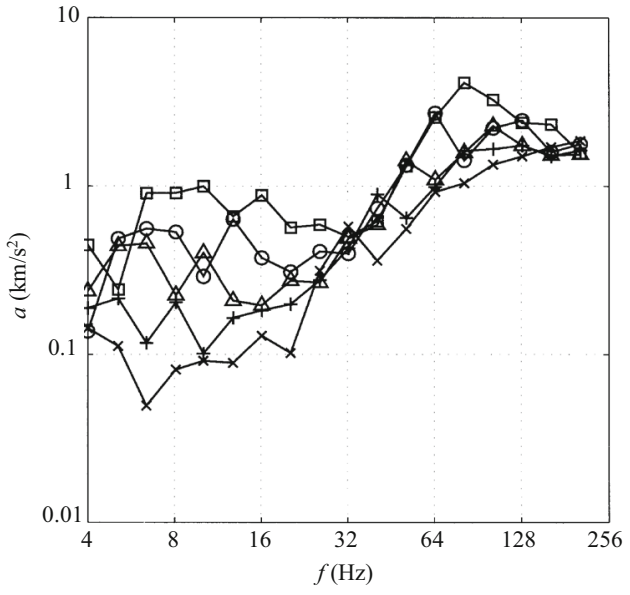

(a)

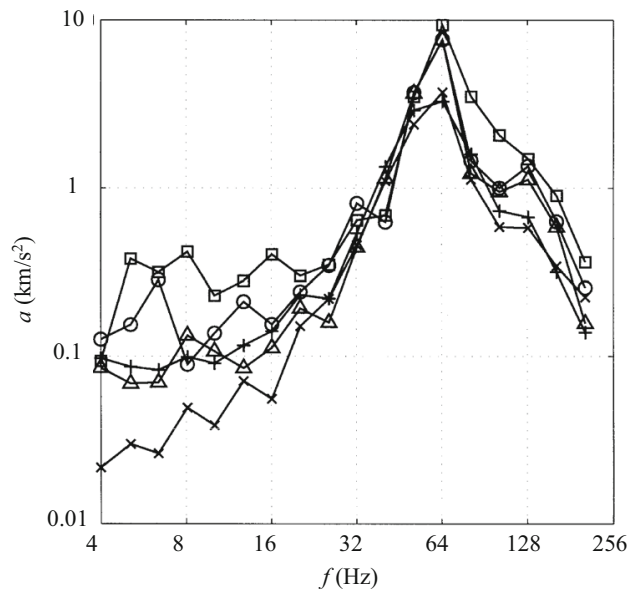

(b)

ㅁ $V_{\mathrm{T}}=160 \mathrm{~km} / \mathrm{h} \quad V_{\mathrm{T}}=125 \mathrm{~km} / \mathrm{h} \Delta V_{\mathrm{T}}=100 \mathrm{~km} / \mathrm{h} \quad+V_{\mathrm{T}}=80 \mathrm{~km} / \mathrm{h} \quad \times \quad V_{\mathrm{T}}=64 \mathrm{~km} / \mathrm{h}$

Fig. 6 Measured wheelset accelerations for different train speeds: $\mathbf{a}$ at a ballast track and $\mathbf{b}$ at a slab track

$200 \mathrm{~Hz}$. The high-frequency transfer function is almost constant where the highest values are reached for the stiffest ballast.

If soft track elements are introduced in the track, the vehicle-track resonance frequency is lower and the highfrequency transfer values are correspondingly reduced. Soft rail pads yield resonance frequencies down to $40 \mathrm{~Hz}$ (Fig. 4c), and soft sleeper pads have resonance frequencies between 20 and $64 \mathrm{~Hz}$ (Fig. 4d). The dynamic axle-loads can thus be reduced to less than one tenth of the values of a standard ballast track.

Now, the experimental results of emission are shown in Figs. 5 and 6 for an almost homogeneous site with a shear wave velocity of $v_{\mathrm{S}}=270 \mathrm{~m} / \mathrm{s}$. An irregularity spectrum has been specified (Fig. 5a) which includes a strongly decreasing alignment error, a weakly decreasing roughness of the rail and wheel, the sleeper passing component $(0.012 \mathrm{~mm})$ and a first out-of-roundness of the wheel $(0.1 \mathrm{~mm})$. These irregularities are shifted in frequency according to the train speeds of $v_{\mathrm{T}}=63$ to $160 \mathrm{~km} / \mathrm{h}$. For these irregularities, the forces acting on the track (and ground) have been calculated (Fig. 5b). The strongly decreasing irregularities (together with the strongly increasing transfer functions) yield almost constant forces which lie around $1 \mathrm{kN}$, a value which can be used as a first approximation. The forces have a weak maximum at $90 \mathrm{~Hz}$ 
due to the vehicle-track resonance frequency. The increasing train speeds yield strongly increasing force amplitudes at low frequencies and a weaker increase at high frequencies. Finally, axle-box measurements are presented for this case in Fig. 6a [53]. All characteristics of the predicted forces can well be found in the measurement results, mainly the almost constant spectra, the strong increase with train speed at low frequencies, and the shift in frequency for the singular components of the out-ofroundness $(6-16 \mathrm{~Hz})$ and the sleeper passage $(32-80 \mathrm{~Hz})$. If the wheelset accelerations are multiplied by the wheelset mass of $1500 \mathrm{~kg}$, the amplitudes of the excitation force can be confirmed.

Figure $6 \mathrm{~b}$ shows a similar measurement result for a slab track. The slab track has soft rail pads which yield a lower vehicle-track resonance at $64 \mathrm{~Hz}$ and a stronger resonance amplitude because of the reduced track damping. So, the vehicle-track resonance can be clearly seen for the slab track, whereas the sleeper passage frequency can better be followed for the ballast track. By these measurements, the prediction of forces as a result from irregularities is confirmed.

\section{Transmission: approximate methods for the prediction of train-induced ground vibration}

The prediction of "transmission" means to calculate the response of the soil (particle velocity spectra) at different distances from the track due to the excitation force spectrum which has been calculated in the emission part. The transfer function of the soil is calculated for a fixed load (as in the US standard [7]). Thus, any moving load effect is excluded and the rare case of trans-Rayleigh trains is not covered by this prediction method. The transfer functions of layered soils are calculated by the "frequency-dependent half-space model", that is a homogeneous half-space of which the stiffness varies with frequency. This concept is based on the fact that the dominant Rayleigh wave reaches down to a certain portion of its wavelength, and this means down to a frequency-dependent depth. The prediction of the transmission consists of the following three steps:

1. the calculation of the approximate dispersion for the layered soil,

2. the calculation of the frequency-dependent point-load solutions,
3. and the superposition of point loads to get the train load.

\subsection{Approximative dispersion of a layered soil}

The exact dispersion curves of layered, multi-layered and continuously layered soils have been used to derive an approximate calculation of the Rayleigh wave dispersion $v_{\mathrm{R}}(f)$ from the soil profile $v_{\mathrm{S}}(z)$. It is based on the approximated dispersion of a layer on a stiffer half-space with the wave velocities of the Rayleigh waves $v_{\mathrm{R} 1}$ and $v_{\mathrm{R} 2}$, as

$$
\begin{aligned}
& v_{\mathrm{R}}(f)=v_{\mathrm{R} 1}+\left(v_{\mathrm{R} 2}-v_{\mathrm{R} 1}\right) 0.5\left(1+\cos \frac{\pi}{2} \frac{f}{f_{1}}\right) \text { with } \\
& f_{1}=\frac{v_{\mathrm{S} 1}}{3 h_{1}},
\end{aligned}
$$

which is extended to a multi-layered situation. A correction for each layer is added to the wave speed $v_{\mathrm{R} 1}$ of the top layer

$$
\begin{gathered}
v_{\mathrm{R}}(f)=v_{\mathrm{R} 1}+\sum_{i=1}^{n-1}\left(v_{\mathrm{R} i}+1-v_{\mathrm{R} i}\right) 0.5\left(1+\cos \frac{\pi f}{2} \frac{f_{i}}{i}\right) \text { with } \\
f_{i}=\frac{v_{\mathrm{S} i}}{3 h_{i}},
\end{gathered}
$$

where $h_{i}$ is the depth where the layer $i$ ends. For very low frequencies, the wave speed of the underlying half-space can be reached.

\subsection{Approximative transfer function of a point load}

The amplitudes of a homogeneous soil can be approximated by the asymptotes

$$
\begin{aligned}
H_{\mathrm{P}}(r, f) & =\frac{v}{F}(r, f) \\
& =\frac{f(1-v)}{G r} \exp \left(-D r^{*}\right)\left\{\begin{array}{lll}
1 & \text { for } & r^{*} \leq r_{0}^{*} \\
\sqrt{r / r_{0}^{*}} & \text { for } & r^{*}>r_{0}^{*}
\end{array}\right. \\
\text { with } \quad r^{*}=\frac{2 \pi f r}{v_{\mathrm{S}}} . &
\end{aligned}
$$

The upper part of Eq. (18) describes the static solution which can be used for the near-field and the low-frequency response. At $r^{*}=r_{0}^{*} \approx 2.7$ starts the lower part of Eq. (18), the far field which is dominated by the Rayleigh wave.

The amplitudes of a homogeneous soil can be used to calculate the wave field of an inhomogeneous soil. The amplitudes of the inhomogeneous soil with its dispersion $v_{\mathrm{R}}(f)$ are approximated by the amplitudes of a homogeneous half-space, but for each frequency the half-space has a different wave speed-the wave speed $v_{\mathrm{R}}(f)$. This method 
works very well for a soil with continuously increasing stiffness.

If this method is applied to a clearly layered situation, the following modifications must be included. A frequency-dependent resonance amplification

$V=\frac{1}{1+i 2 D \eta-\eta^{2}}$

can be introduced, where

$$
\begin{gathered}
\eta=\left\{\begin{array}{ll}
f / f_{1} & \text { for } f \leq f_{1} \\
2-f / f_{1} & \text { for } f>f_{1}
\end{array}, \quad f_{1}=\frac{v_{\mathrm{S} 1}}{3 h_{1}}, \quad\right. \text { and } \\
D=\frac{2}{\pi} \frac{\rho_{1} v_{\mathrm{S} 1}}{\rho_{2} v_{\mathrm{S} 2}},
\end{gathered}
$$

are used for the normalized frequency $\eta$, the resonance frequency $f_{1}$, and the damping $D$ is calculated according to the one-dimensional wave theory.

The effect of soft top layers on the low-frequency nearfield and the effect of stiff deeper layers on the high-frequency far field are included by a general procedure. Normally at a certain frequency $f$, the half-space amplitudes of the corresponding wave velocity $v_{\mathrm{R}}(f)$ are calculated. Corrections of the transfer functions are made if deeper and stiffer soil material yields greater half-space amplitudes, or softer top layers yield greater "layer amplitudes" which are approximated by $A_{\mathrm{L}}=A_{\mathrm{H}} \mathrm{e}^{-a r / h}$, according to the low frequency behaviour of a layer on a rigid base. The greatest amplitude is always chosen as the correct transfer function. The method can be improved if the dispersion is shifted one-third of octave to lower frequencies, and if the resonance damping in Eq. (19) is always $D \geq 0.1$.

\subsection{Approximative transfer function of a train load}

The frequency-dependent effect of the track width of $b=2.6 \mathrm{~m}$ is approximated by modifying the force spectrum [54]

$$
\begin{aligned}
& \frac{F^{*}}{F}(f)=\left\{\begin{array}{ll}
\sin \left(b^{*} / 2\right) / b^{*} / 2 & \text { for } b^{*} \leq \pi \\
2 / b^{*} & \text { for } b^{*}>\pi
\end{array}\right. \text { with } \\
& b^{*}=\frac{2 \pi f b}{v_{\mathrm{R}}},
\end{aligned}
$$

where $v_{\mathrm{R}}$ is the velocity of the Rayleigh wave.

The response to a train load is calculated by adding the responses of all $n$ axle loads along the train length $L$ which are considered fixed at their places and as random independent sources

$v(x, f)=\sqrt{\sum_{j=1}^{n} H_{\mathrm{P}}^{2}\left(\sqrt{x^{2}+y_{j}^{2}}, f\right)} F^{*}(f)$, where $n=40$ and $L=250 \mathrm{~m}$ are used as standard values. It has been found by numerical tests that this train length already yields the response of an infinitely long train for normal soils with material damping and for normal distances up to $100 \mathrm{~m}$. That means that the ground vibration amplitudes which are predicted for trains longer than $250 \mathrm{~m}$ are the same as those of a standard train of $L=250 \mathrm{~m}$.

\section{Examples for the transmission of train-induced ground vibrations}

Results are presented for two layered sites, one site with soft soils and one site with stiff soils. The soil parameters have been established from wave velocity measurements [55] as

$$
\begin{aligned}
& v_{\mathrm{S} 1}=125 \mathrm{~m} / \mathrm{s}, v_{\mathrm{S} 2}=350 \mathrm{~m} / \mathrm{s}, h=4 \mathrm{~m}, D=2.5 \% \text { soft } \\
& \text { site, } \\
& v_{\mathrm{S} 1}=325 \mathrm{~m} / \mathrm{s}, v_{\mathrm{S} 2}=850 \mathrm{~m} / \mathrm{s}, h=5 \mathrm{~m}, D=2.5 \% \text { stiff } \\
& \text { site. }
\end{aligned}
$$

The mass density and the Poisson's ratio are assumed as $\rho=2000 \mathrm{~kg} / \mathrm{m}^{3}$ and $v=0.33$. At first, Fig. $7 \mathrm{a}-\mathrm{d}$ shows the transfer functions $v / F$ between the excitation force $F$ and the ground vibration amplitudes $v$ at different distances. The exact point-load solutions (Fig. 7a, b) which are calculated by an infinite wavenumber integral [13] are compared with the approximate solution (Fig. 7c, d). Both solutions show the strong difference between the soft and the stiff soil. The amplitudes of the soft soil are almost a factor 10 higher than the amplitudes of the stiff soil. For each site, the low-frequency amplitudes are low and increasing with frequency. The high-frequency amplitudes are not so increasing in the near field and decreasing in the far field. Big differences between the near and the far field occur, thus yielding a strong attenuation with distance. The far field spectra have a maximum in the mid-frequency range which is characteristic for the layering of the soil. The maximum is at $16 \mathrm{~Hz}$ for the soft soil and at $32 \mathrm{~Hz}$ for the stiff soil. All these details of the point-load transfer function are in good agreement between the time-consuming, exact and the fast, approximate solution.

For the prediction of train-induced ground vibration, many of these point-load transfer functions have been superposed to get the train-load transfer functions in Fig. 7e, f. The train-load transfer functions are closer together than the point-load transfer function. That means that the train-induced ground vibration has less attenuation with distance. The train-induced far field amplitudes are higher than the point-load amplitudes. The high-frequency train-induced amplitudes are reduced so that the near field is almost constant with frequency and the far field has a 


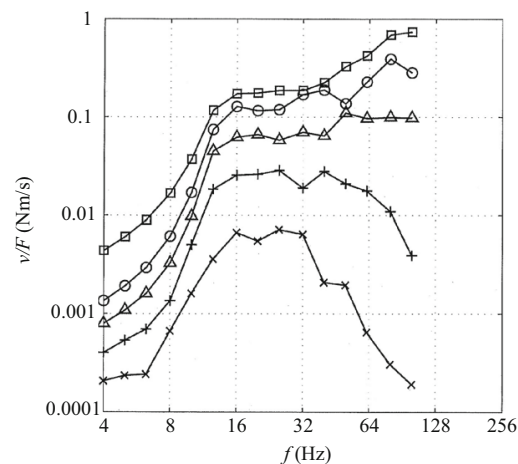

(a)

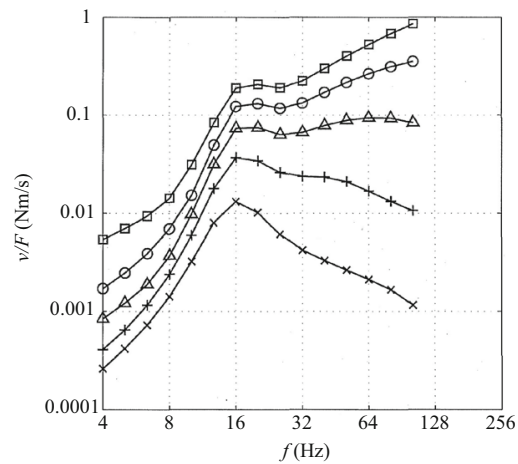

(c)

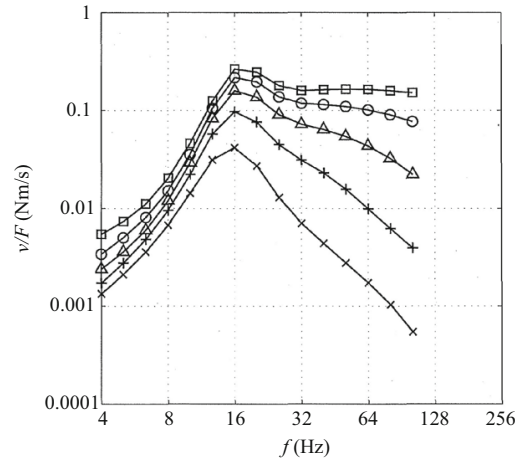

(e)

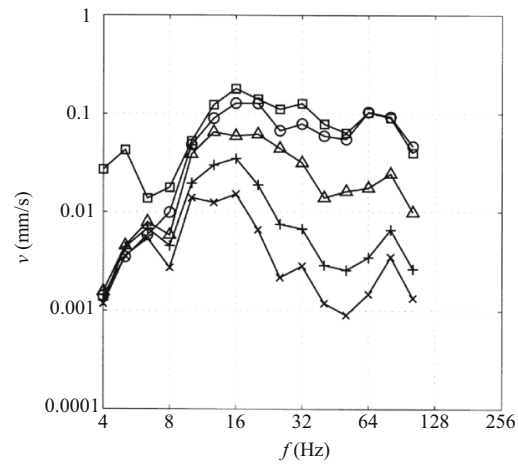

(g)

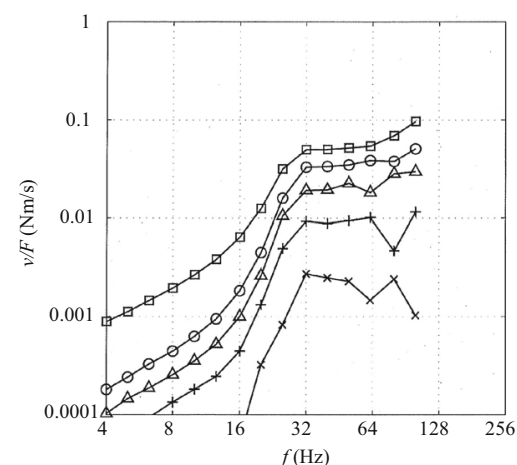

(b)

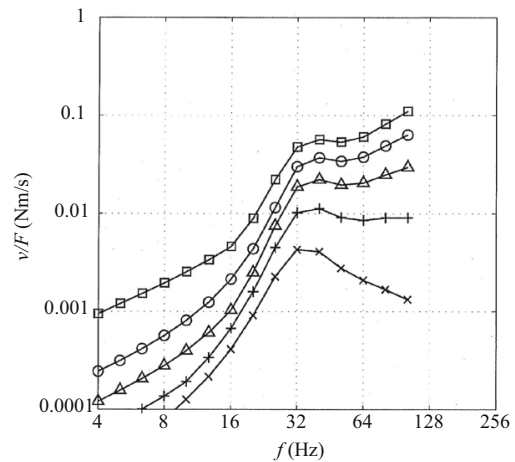

(d)

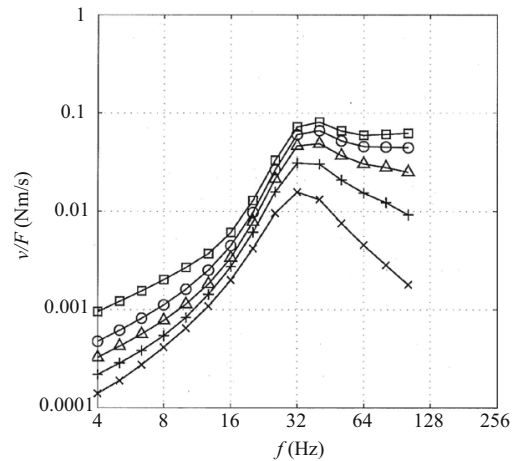

(f)

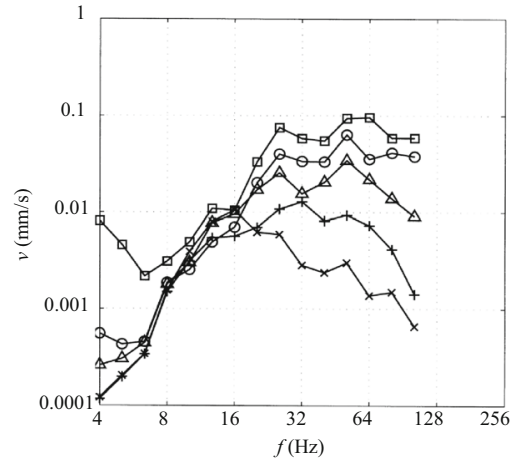

(h)

$\square 4 \mathrm{~m} \quad \circ 8 \mathrm{~m} \quad \Delta 16 \mathrm{~m}+32 \mathrm{~m} \quad \times 64 \mathrm{~m}$

Fig. 7 Ground vibration at a soft layered site $(\mathbf{a}, \mathbf{c}, \mathbf{e}, \mathbf{g})$ and at a stiff layered site $(\mathbf{b}, \mathbf{d}, \mathbf{f}, \mathbf{h})$ at different distances: $\mathbf{a}, \mathbf{b}$ exact point-load transfer functions; $\mathbf{c}, \mathbf{d}$ approximated point-load transfer functions; $\mathbf{e}, \mathbf{f}$ train-load transfer functions; $\mathbf{g}, \mathbf{h}$ measured train-induced ground vibrations 
stronger reduction with frequency. At the end, if the soft and stiff soil are compared, the soft soil has much higher amplitudes at low frequencies, but similar amplitudes as the stiff soil at high frequencies.

Finally, some passages of passenger trains with train speeds trains between 100 and $160 \mathrm{~km} / \mathrm{h}$ are presented in Fig. $7 \mathrm{~g}, \mathrm{~h}$ from a measurement campaign in Switzerland [53]. The train-induced spectra are very similar to the transfer functions. This good agreement between measurement and prediction means that a wheelset force of 1 $\mathrm{kN}$ per third of octave band is a suitable assumption for the prediction. Train specific components can be found in the measurements. At frequencies below $8 \mathrm{~Hz}$, the amplitudes measured at $4 \mathrm{~m}$ are higher than the measured ones (the quasi-static response), and at $50 \mathrm{~Hz}$ in Fig. $7 \mathrm{~h}$ and at $80 \mathrm{~Hz}$ in Fig. $7 \mathrm{~g}$, a peak can be observed which is caused by the passage of the wheels over the equally spaced sleepers. The train-induced spectra represent all the characteristics of the soft and stiff layered soils. These examples demonstrate the necessity to evaluate soil-dependent predictions.

\section{Immission: the building response to the free- field vibrations}

A simplified building model has been established which consists of the foundation stiffness, the rising structure (column or wall) and the floors at each storey (Fig. 8). The model captures the important effects of soil-structure interaction, of floor resonances and of deformable walls and columns. This simple model can be applied for the whole building, giving average results, or to a regular vertical section of the building. Buildings are very complex structures so that a detailed model should be calculated if possible, for example when a new building is planned near a railway line (see some examples in [58]).

\subsection{The dynamic foundation stiffness (soil-structure interaction)}

The soil is represented by a spring and a damper element. The spring and damper parameters for a rigid circular foundation on a homogeneous soil are

$k \approx 3.4 G \sqrt{A_{\mathrm{S}}}$ and $c \approx 1.6 \sqrt{G \rho} A_{\mathrm{S}}=1.6 \rho v_{\mathrm{S}} A_{\mathrm{S}}$,

with foundation area $A_{\mathrm{S}}$, shear modulus $G$, mass density $\rho$ and shear wave velocity $v_{\mathrm{S}}$ of the soil. These parameters are used as a standard. They can be checked against detailed calculations [56]. These soil elements are excited by the freefield vibrations $u_{0}$ at their lower ends (see Fig. 8).

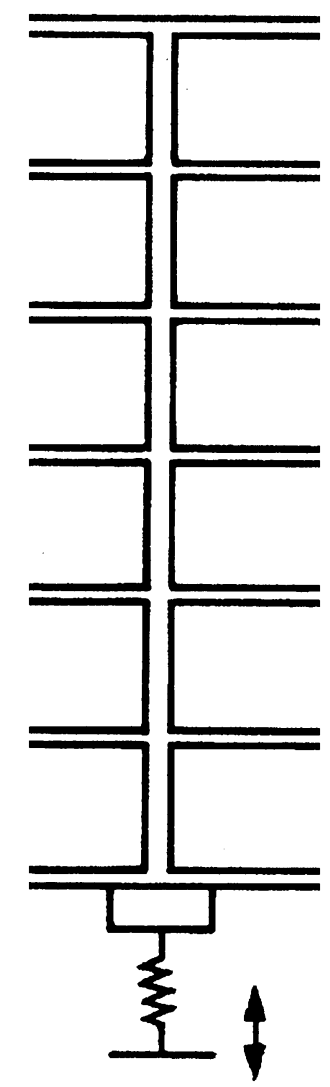

Fig. 8 Simplified building model consisting of the soil, a wall or column and the floors

\subsection{Floor vibrations and their feedback on the building structure}

The floor with mass $m_{\mathrm{F}}$, damping $D$ and eigenfrequency $f_{\mathrm{F}}$ is described by two transfer functions of frequency $f$ between the wall displacement $u_{\mathrm{W}}$ at the floor support and the displacement $u_{\mathrm{F}}$ at mid-span and the support force $F_{\mathrm{W}}$ :

$\frac{u_{\mathrm{F}}}{u_{\mathrm{W}}}=1+\alpha \frac{f^{2}}{(1+2 D i) f_{\mathrm{F}}^{2}-f^{2}}$,

$\frac{F_{\mathrm{W}}}{u_{\mathrm{W}}}=(2 \pi f)^{2} m_{\mathrm{F}}\left(1+\frac{f^{2}}{(1+2 D i) f_{\mathrm{F}}^{2}-f^{2}}\right)$.

The transfer functions are given for the first mode $v$ of the floor, and the parameters follow as [57]

$\alpha=\frac{v\left(x_{\mathrm{F}}\right) \int v \mathrm{~d} m}{\int v^{2} \mathrm{~d} m}$,

$\mu=\frac{\left(\int v \mathrm{~d} m\right)^{2}}{m_{\mathrm{F}} \int v^{2} \mathrm{~d} m}$.

The values $\alpha$ and $\mu$ vary with the mode shape $v(x)$. For a square floor area, the values are given in Table 3 for different boundary conditions. In the order 4 sides clamped, 4 
Table 2 Parameters of the immission part

\begin{tabular}{lll}
\hline Elasticity modulus of concrete & $E_{\mathrm{C}}$ & $30 \times 10^{9} \mathrm{~N} / \mathrm{m}^{2}$ \\
Elasticity modulus of masonry & $E_{\mathrm{M}}$ & $5 \times 10^{9} \mathrm{~N} / \mathrm{m}^{2}$ \\
$\begin{array}{l}\text { Mass density of concrete } \\
\quad\end{array}$ & $\rho$ & $2500 \mathrm{~kg} / \mathrm{m}^{3}$ \\
and masonry & $H$ & $12-60 \mathrm{~m}$ \\
Height of the building & $h$ & $3 \mathrm{~m}$ \\
Height of the storey & $n$ & $4-20$ \\
Number of storeys & $l_{\mathrm{F}}$ & $6 \mathrm{~m}(5 \mathrm{~m})$ \\
Length and width of a floor & $d_{\mathrm{F}}$ & $0.2 \mathrm{~m}$ \\
Thickness of the floor & $d_{\mathrm{W}}$ & $0.25 \mathrm{~m}$ \\
Thickness of the wall & $d_{\mathrm{C}}$ & $0.6 \mathrm{~m}$ \\
Thickness of the column & $v_{\mathrm{S}}$ & $200(100-300) \mathrm{m} / \mathrm{s}$ \\
Shear wave velocity of the soil & $A_{\mathrm{S}}$ & $2 \mathrm{~m} \times 2 \mathrm{~m}=4 \mathrm{~m}{ }^{2}$ \\
Soil area & $k$ & $540(300-1200) \times 10^{6} \mathrm{~N} / \mathrm{m}$ \\
Soil foundation stiffness & $c$ & $2.4(1.8-3.6) \times 10^{6} \mathrm{Ns} / \mathrm{m}$ \\
Soil foundation damping & &
\end{tabular}

sides hinged, 2 sides clamped, 2 sides hinged, 4 corners clamped, 4 corners hinged, the mass ratio $\mu$ is increasing and displacement factor $\alpha$ is decreasing or almost constant.

\subsection{Transfer matrix of a wall-, floor- and soil- element}

Transfer matrices describe the transfer of the displacement and force from the bottom to the top of a building element

$\left[\begin{array}{l}F_{1} \\ u_{1}\end{array}\right]=\left[\begin{array}{ll}T_{11} & T_{12} \\ T_{21} & T_{22}\end{array}\right]\left[\begin{array}{l}F_{2} \\ u_{2}\end{array}\right]$.

The transfer matrix of a wall element with the storey height $h$ and the cross section $A_{\mathrm{W}}$ is

$\boldsymbol{T}_{\mathrm{W}}=\left[\begin{array}{cc}\cos a & -\sin a \cdot k_{\mathrm{W}} a \\ \sin a / k_{\mathrm{W}} a & \cos a\end{array}\right]$,

with the static stiffness $k_{\mathrm{W}}=E A_{\mathrm{W}} / h$, the dimensionless wave parameter $a=\omega h / v_{\mathrm{L}}$, and the longitudinal wave velocity $v_{\mathrm{L}}$ of the wall. This transfer matrix results in considerable wave propagation along the height of the building. The transfer matrix for a rigid or flexible floor is

$\boldsymbol{T}_{\mathrm{R}}=\left[\begin{array}{cc}1 & -m^{2} \\ 0 & 1\end{array}\right] \quad \boldsymbol{T}_{\mathrm{F}}=\left[\begin{array}{cc}1 & F_{\mathrm{W}} / u_{\mathrm{W}} \\ 0 & 1\end{array}\right]$

and the transfer matrix of the soil element is

$\boldsymbol{T}_{\mathrm{S}}=\left[\begin{array}{cc}1 & 0 \\ 1 /(k+c i \omega) & 1\end{array}\right]$.

The whole building (for example a four-storey building) is represented by the matrix chain

$\boldsymbol{T}_{\mathrm{B}}=\boldsymbol{T}_{\mathrm{S}} \boldsymbol{T}_{\mathrm{F}} \boldsymbol{T}_{\mathrm{W}} \boldsymbol{T}_{\mathrm{F}} \boldsymbol{T}_{\mathrm{W}} \boldsymbol{T}_{\mathrm{F}} \boldsymbol{T}_{\mathrm{W}} \boldsymbol{T}_{\mathrm{F}} \boldsymbol{T}_{\mathrm{W}} \boldsymbol{T}_{\mathrm{F}}$.
The boundary condition $F=0$ at the roof is used to evaluate the foundation force $F_{0}=T_{\mathrm{B} 12} / T_{\mathrm{B} 22} u_{0}$, and all response quantities at walls and floors can then be calculated by the free-field excitation $u_{0}, F_{0}$, the transfer matrices and the transfer function $u_{\mathrm{F}} / u_{\mathrm{W}}$ (Eq. (24)) of the floor.

\section{The vibration response for different types of buildings}

Some building examples have been analysed by this simple prediction method and by the three-dimensional finiteelement method [58] for comparison, some column-type office buildings of four to twenty storeys and a wall-type apartment building. The material and geometric parameters of these buildings are given in Table 2 .

\subsection{A four-storey apartment building}

A four-storey apartment building with masonry walls and concrete floors has been analysed on a medium stiff soil. The transfer functions between the free field and the building components are shown in Fig. 9. These transfer functions show some general characteristics. All freefieldbuilding transfer functions start with $V=1$ at zero frequency and usually end below $V<1$ at $50 \mathrm{~Hz}$. That means that the free field is not modified by the building at low frequencies whereas the free field is reduced by the building at high frequencies. In between, amplifications of the free field can occur due to several reasons. At $10 \mathrm{~Hz}$, the resonance of the building on the compliant soil can be found with amplitudes of $V=5$ to 6 . This building-soil resonance frequency is determined by the stiffness $k$ of the soil and the mass $m$ of the building as $f_{\mathrm{s}}=\sqrt{k / m}$. As a consequence, the building-soil resonance frequency should be proportional to the shear wave velocity of the soil $f_{\mathrm{s}} \sim V_{\mathrm{s}}=\sqrt{G / \rho}$ and indirectly proportional to the square root of the number of storeys $f_{\mathrm{s}} \sim \sqrt{n}$.

Next at $25 \mathrm{~Hz}$, some smaller amplifications can be found which are due to the floor resonances. The floor resonance frequencies are ruled by the width $(5 \mathrm{~m} \times 5 \mathrm{~m})$, the thickness $(0.2 \mathrm{~m})$ and the support conditions (clampedclamped) of the floor (Fig. 10a). Finally, another characteristic behaviour can be observed at $37 \mathrm{~Hz}$ where the floors and the walls are vibrating in anti-phase (Fig. 10b). The results for the finite-element model are also given in Figs. 9c, d. The agreement of the one-dimensional prediction model with the three-dimensional finite-element model is very good. 


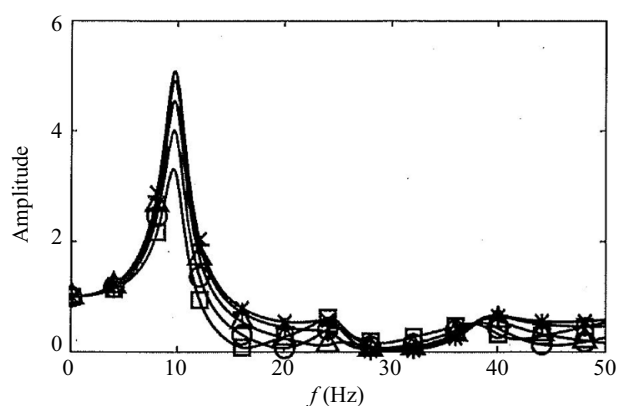

(a)

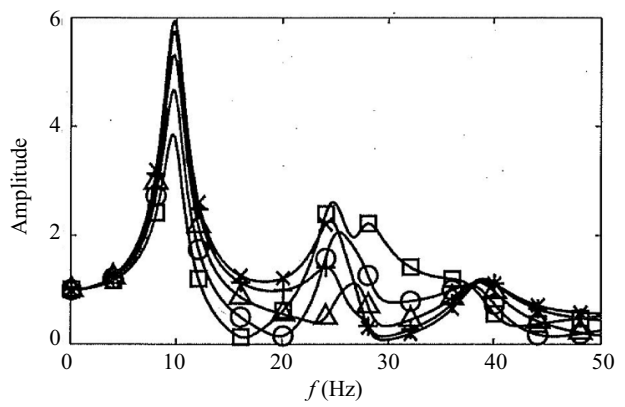

(c)

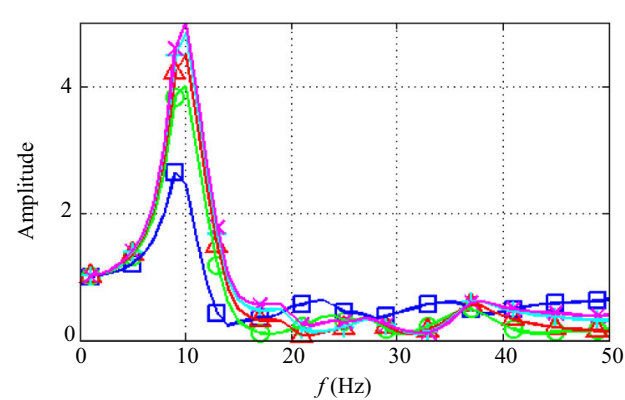

(b)

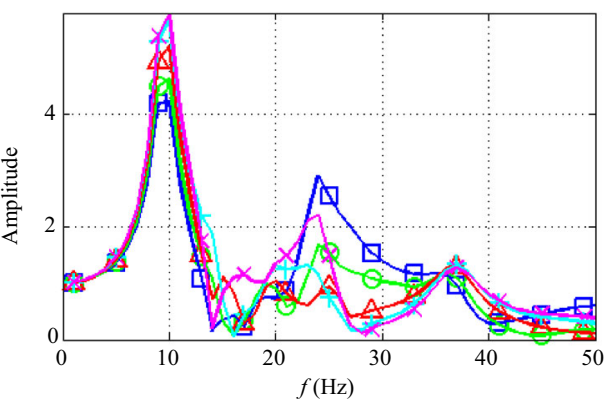

(d)

$\square$ Ground floor $\bigcirc$ First floor $\Delta$ Second floor + Third floor $\times$ Roof

Fig. 9 Soil-building transfer functions of a four-storey apartment building: a, b wall; $\mathbf{c}, \mathbf{d}$ floors; $\mathbf{a}, \mathbf{c}$ one-dimensional prediction model; $\mathbf{b}$, d three-dimensional finite-element model

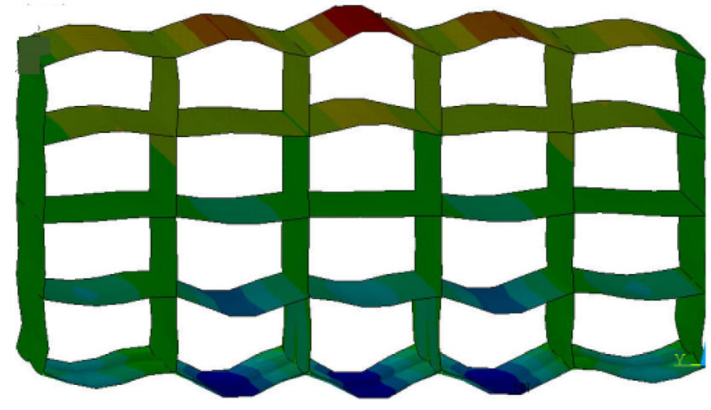

(a)

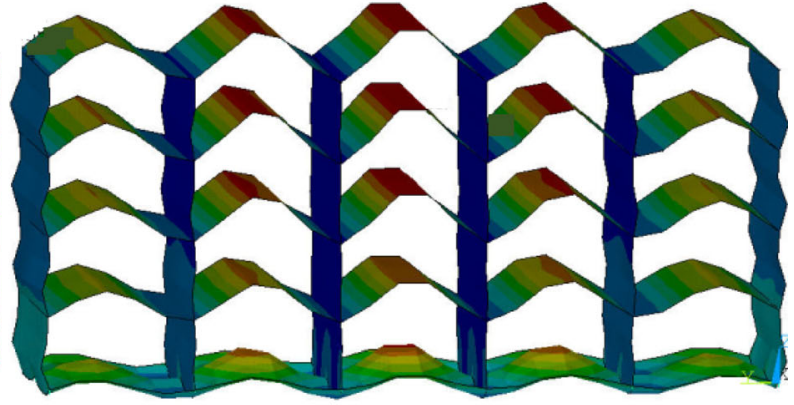

(b)

Fig. 10 Vibration modes of the apartment building at a $24 \mathrm{~Hz}$ and $\mathbf{b} 37 \mathrm{~Hz}$

\subsection{A twenty-storey office tower}

The twenty-storey office tower presents another characteristic of building vibration. Figure 11 shows a vibration mode where the amplitudes increase with increasing storey number. This vibration mode is called the column mode because the deformation of the columns is the main reason of this vibration. The column frequency is determined by the wave velocity $v_{\mathrm{L}}$ of the columns (and floors) and the height $H$ of the building $f_{\mathrm{C}}=v_{\mathrm{L}} / 4 H$. The column frequency indicates an amplification of the amplitudes with height and a resonance in case of a stiff soil. The column frequency of the office tower is $f_{\mathrm{C}}=6 \mathrm{~Hz}$, and the soilbuilding resonance is also at $6 \mathrm{~Hz}$. So, both modes (the soil and the column mode) work together, amplifying each other and resulting in a basic building resonance at $4 \mathrm{~Hz}$ which can be found for the prediction as well as for the finite-element model (Fig. 12a, b). The office tower has the lowest resonance frequency and the highest resonance amplitudes of all building examples, but at the same time all amplitudes above $10 \mathrm{~Hz}$ are quite small, below $V=1$.

It should be noted that the apartment building of the preceding section has also a relevant column (wall) frequency at $f_{\mathrm{C}}=19 \mathrm{~Hz}$ because of the softer masonry 


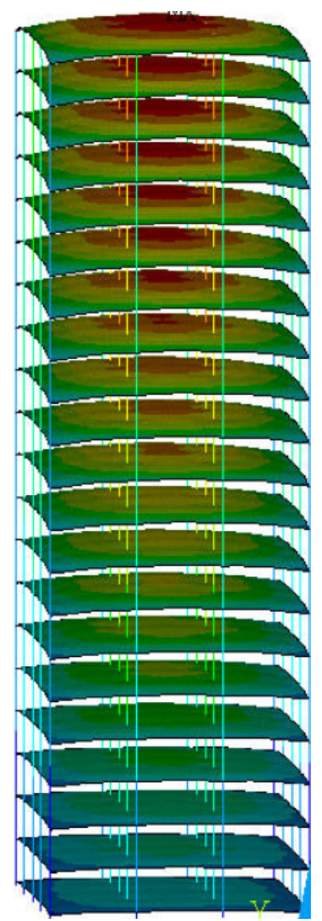

Fig. 11 Vibration mode of the office tower at $4 \mathrm{~Hz}$

material. Due to the soft material, the low-rise apartment building has a low wall frequency and the deformations of the wall have an influence on the basic building resonance shifting it from 12 to $10 \mathrm{~Hz}$ (Fig. 9a).

\subsection{Some parameter variations for office buildings}

The office buildings are built with concrete columns of cross section $0.6 \mathrm{~m} \times 0.6 \mathrm{~m}$ and concrete floors of dimensions $6 \mathrm{~m} \times 6 \mathrm{~m} \times 0.2 \mathrm{~m}$. A four-storey office building is shown in Fig. 13 with its soil-building transfer

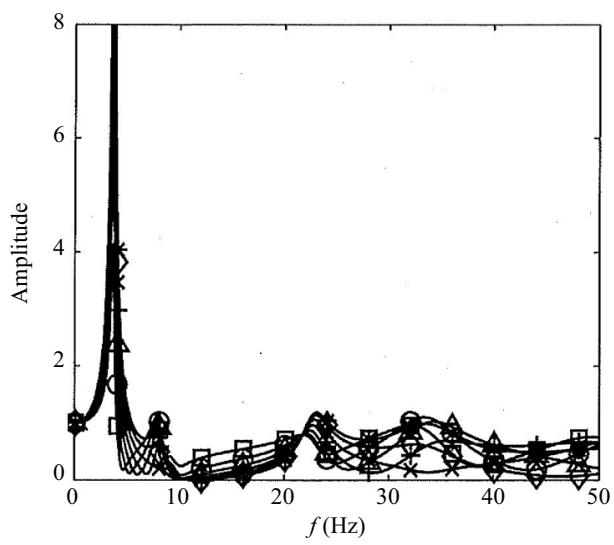

(a) functions. The basic building resonance at $9 \mathrm{~Hz}$ is dominant. Some small floor resonances can be observed at $12 \mathrm{~Hz}$. At the same frequency, the column amplitudes are clearly reduced. More office buildings on different soils and with different number of storeys are presented in Fig. 14 with average column and floor transfer functions. The floor resonances are at quite low frequencies around 12 $\mathrm{Hz}$ for the column-type office buildings. Therefore, the floor vibrations have an influence on the basic building resonance and reduce its resonance frequency which lies between $7 \mathrm{~Hz}$ for the softest soil and $10 \mathrm{~Hz}$ for the stiffest soil (Fig. 14a-d). The same presentation is given in Fig. $14 \mathrm{e}-\mathrm{h}$ for the variation of the number of storeys. The calculated basic building resonance frequency can be compared with the theoretical soil, floor and column frequencies where the closest theoretical frequencies have the strongest influence. The four-storey building has a calculated basic building resonance frequency of $f_{\mathrm{B}}=9 \mathrm{~Hz}$ which is influenced by the soil frequency of $f_{\mathrm{S}}=14.4 \mathrm{~Hz}$ and the floor frequency of $f_{\mathrm{F}}=13.7 \mathrm{~Hz}$. The twelve-storey building has a basic frequency of $f_{\mathrm{B}}=6 \mathrm{~Hz}$ which is influenced by the soil frequency of $f_{\mathrm{S}}=8.8 \mathrm{~Hz}$ and the column frequency of $f_{\mathrm{C}}=10.3 \mathrm{~Hz}$. To conclude, all interactions of floor, column and soil modes in all building models are well represented by the simple building model in good agreement with the three-dimensional finite-element model.

\subsection{Measurement results}

Finally, two measurement examples are shown in Fig. 15 [59]. Both buildings have a column-type structure. The first building is a four-storey concrete building, and the second building is a six-storey steel-frame construction. Both buildings show some floor resonances, the first building at

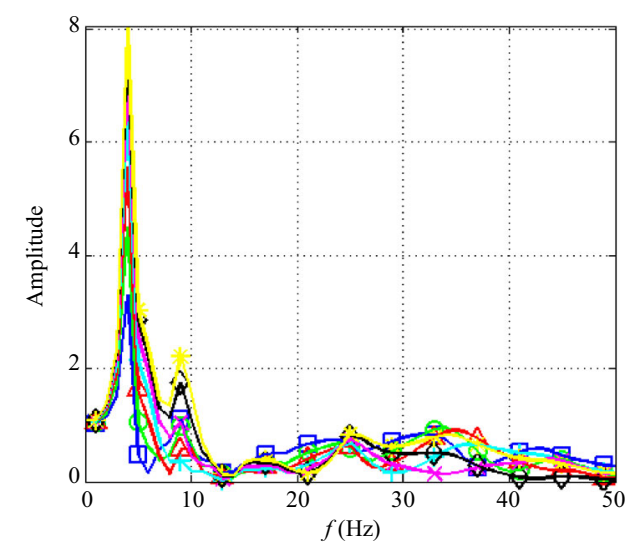

(b)

Cloumn at $\square$ ground, $\bigcirc$ 3rd, $\triangle 6$ th, +9 th, $\times 12$ th, $\diamond 15$ th, $* 18$ th storey

Fig. 12 Soil-building transfer functions of the office tower: a prediction model and $\mathbf{b}$ finite-element model 


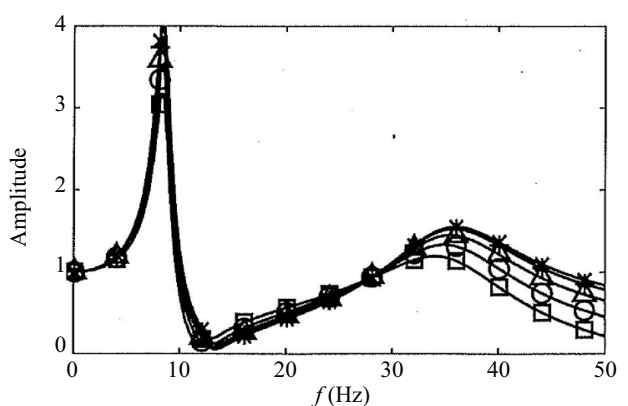

(a)

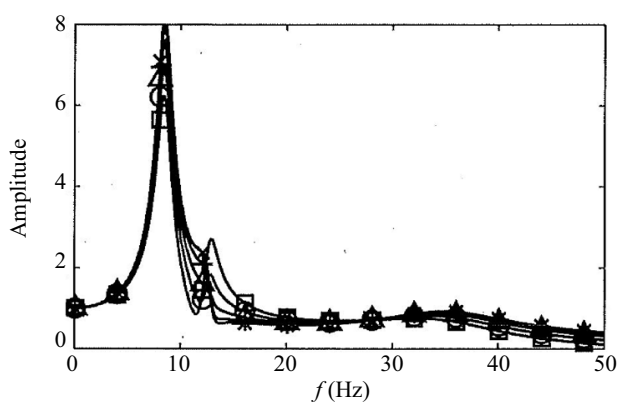

(c)

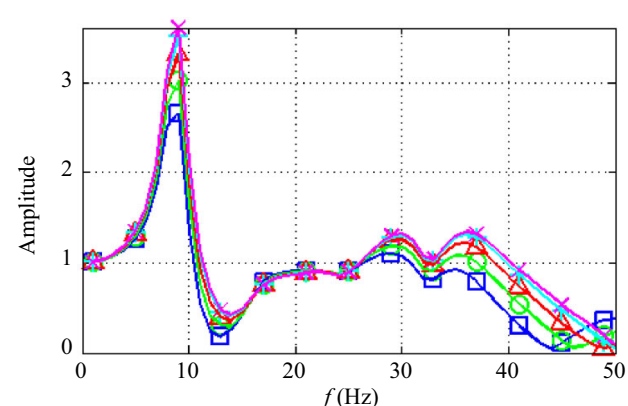

(b)

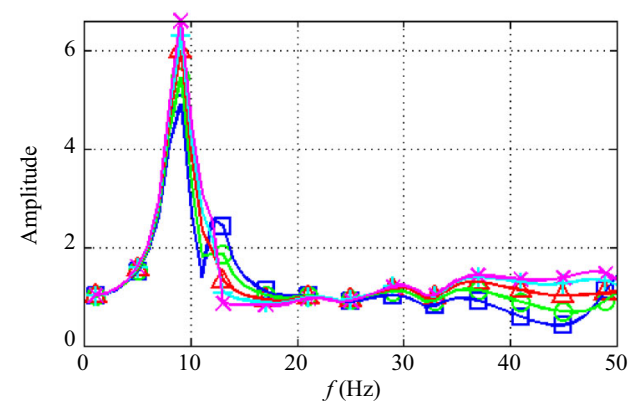

(d)

$\square$ Ground floor $\bigcirc$ First floor $\Delta$ Second floor + Third floor $\times$ Roof

Fig. 13 Soil-building transfer functions of the four-storey office building: a, b column; c, d floors; a, c prediction model; b, d finite-element model

$12.5 \mathrm{~Hz}$, the second building between 15 and $20 \mathrm{~Hz}$. Most typical, both column-type buildings have a dominant first resonance at $7.5 \mathrm{~Hz}$ and $10 \mathrm{~Hz}$, respectively. The amplitudes are increasing with the number of storeys which can clearly be observed in Fig. 15b. For the four-storey building (Fig. 15a), this difference can also be seen between the first and the third storey, but also the influence of the amplified floors can be seen. The first building resonance is therefore clearly identified as a combination of the column mode and the floor mode. For frequencies higher than the building and the floor resonance frequencies, the amplitudes are clearly reduced. The measured reduction is stronger than the calculated reduction for the detailed and the simple models. The reason for the stronger reduction may be a softer soil in the measurements or a higher building mass for example of the non-bearing members which are not included in the models. In general, these building examples offer proof for the practical relevance of the investigated phenomena of column-type buildings.

\section{Conclusions}

A simple and fast prediction scheme has been presented for train-induced ground and building vibrations. All formula for the vehicle-track, soil and building models have been given in this article. It has been demonstrated that the results of all simple models can well represent the behaviour of more detailed models, three-dimensional finiteelement boundary-element track models, wavenumber integrals for layered soil models, and three-dimensional finite-element building models. Moreover, measurement examples have been given for the emission (two track examples measured from axle boxes), transmission (twolayered soil examples) and immission (two multi-storey column-type office buildings) which underline the practical value of the prediction. The characteristic behaviour of the different components has been demonstrated by example predictions.

- The strongly decreasing irregularity spectra and the strongly increasing vehicle-track transfer function lead to almost constant excitation forces. 


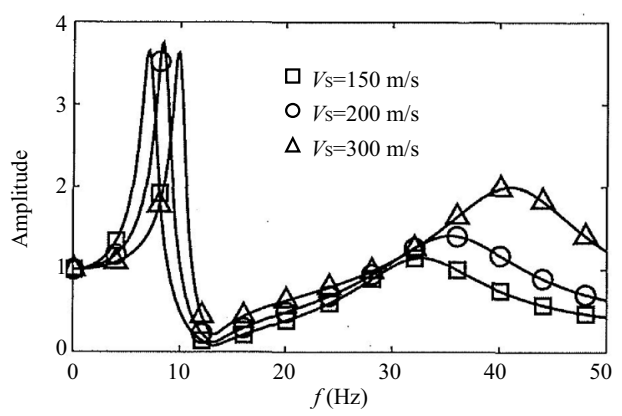

(a)

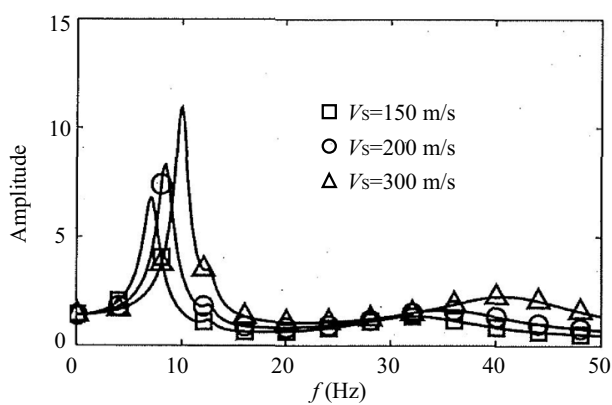

(c)

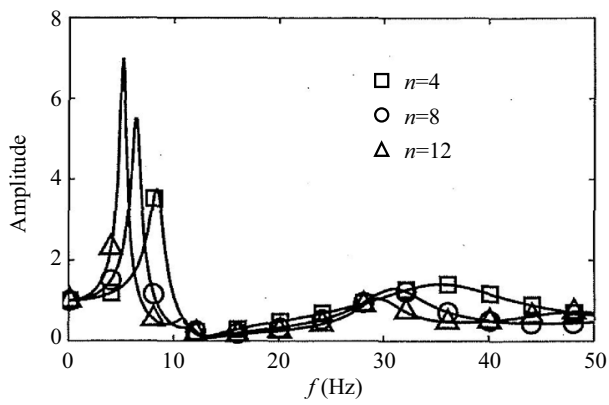

(e)

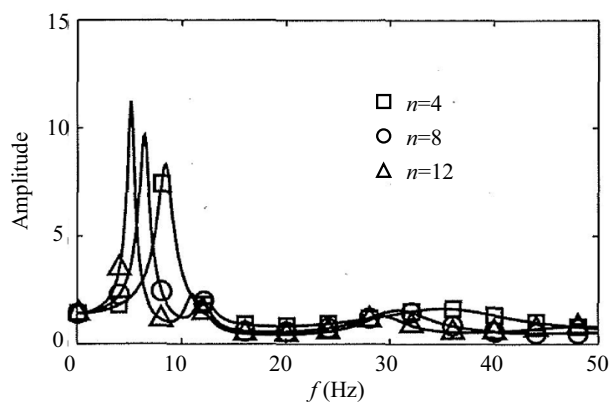

(g)

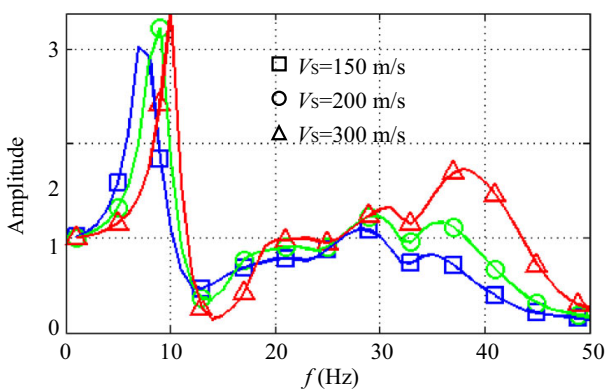

(b)

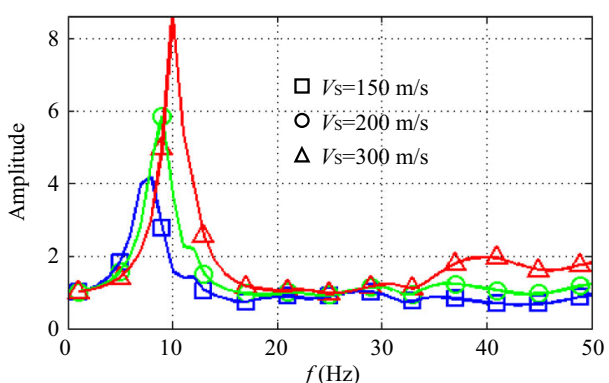

(d)

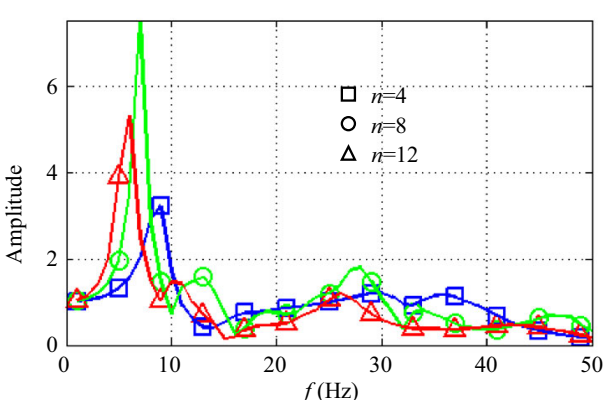

(f)

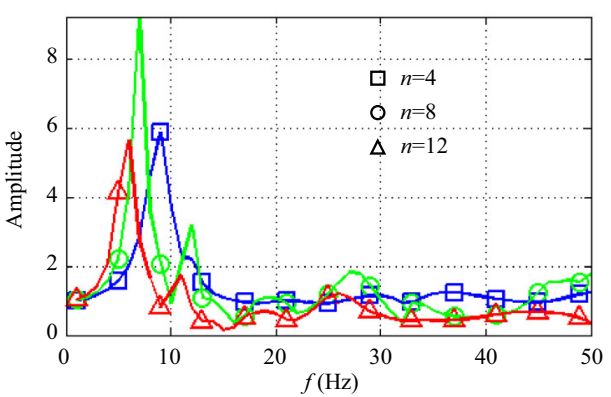

(h)

Fig. 14 Averaged soil-column $(\mathbf{a}, \mathbf{b}, \mathbf{e}, \mathbf{f})$ and soil-floor $(\mathbf{c}, \mathbf{d}, \mathbf{g}, \mathbf{h})$ transfer functions of office buildings with a-d different soils, and with $\mathbf{e}-$ h different number of storeys $\left(V_{\mathrm{S}}=200 \mathrm{~m} / \mathrm{s}\right)$

- Elastic track elements shift the vehicle-track-soil resonance frequency and yield a reduction in the excitation force.

- The wave propagation through layered soils is strongly frequency dependent. The deeper stiff soil yields small low-frequency amplitudes, whereas the softer top layer yields greater high-frequency amplitudes. Moreover, a clear difference between a soft and a stiff site has been calculated and measured. Therefore, a site-specific prediction of train-induced ground vibration is absolutely essential. 


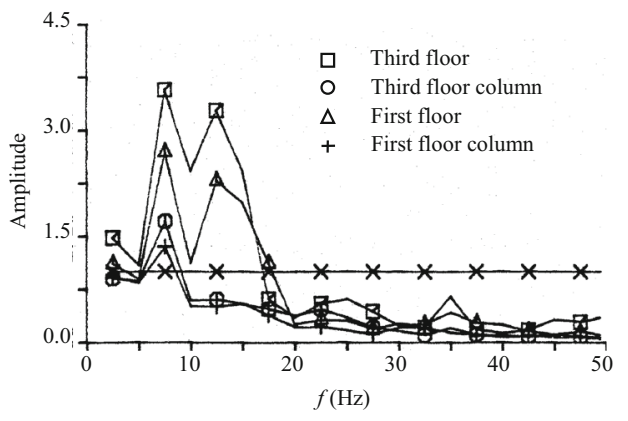

(a)

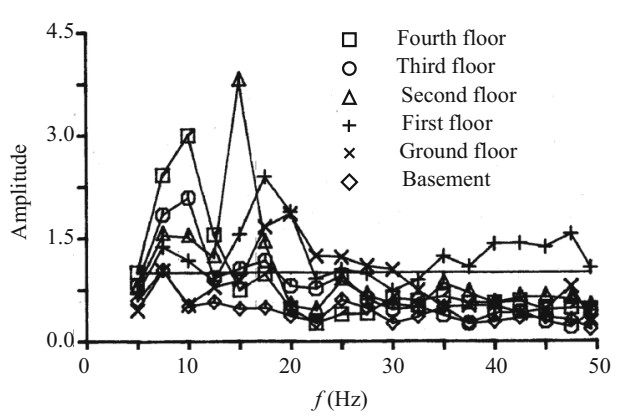

(b)

Fig. 15 Measured soil-building transfer functions of two office buildings: a a four-storey concrete building; b a six-storey steel-frame building

Table 3 Parameters of square floors

\begin{tabular}{llll}
\hline Boundary condition & $f_{0}^{*}(\mathrm{~Hz})$ & $\alpha$ & $\mu$ \\
\hline 4 Sides clamped & 32 & 1.72 & 0.46 \\
4 Sides hinged & 17.8 & 1.62 & 0.65 \\
2 Sides clamped & 20 & 1.31 & 0.67 \\
2 Sides hinged & 8.8 & 1.3 & 0.78 \\
4 Corners clamped & 8.4 & 1.39 & 0.88 \\
4 Corners hinged & 6.4 & 1.33 & 0.91 \\
\hline
\end{tabular}

$* d_{\mathrm{F}}=0.2 \mathrm{~m}, l_{\mathrm{F}}=0.6 \mathrm{~m}$, concrete

- Floor, column and soil modes have been observed in apartment and office buildings. The analysis of different number of storeys and different stiffnesses of the soil shows the coupling between these modes which leads to lower resonance frequencies and higher resonance amplitudes. These phenomena are in a very good agreement between the simple one-dimensional prediction model and the three-dimensional finiteelement model.

Open Access This article is licensed under a Creative Commons Attribution 4.0 International License, which permits use, sharing, adaptation, distribution and reproduction in any medium or format, as long as you give appropriate credit to the original author(s) and the source, provide a link to the Creative Commons licence, and indicate if changes were made. The images or other third party material in this article are included in the article's Creative Commons licence, unless indicated otherwise in a credit line to the material. If material is not included in the article's Creative Commons licence and your intended use is not permitted by statutory regulation or exceeds the permitted use, you will need to obtain permission directly from the copyright holder. To view a copy of this licence, visit http://creativecommons. org/licenses/by/4.0/.

\section{References}

1. Rücker W, Auersch L, Gerstberger U, Meinhardt C (2005) A practical method for the prediction of railway vibration. In: Proceedings of 6th international conference on structural dynamics (EURODYN 2005), Millpress, Rotterdam, pp 601-606
2. Auersch L, Gerstberger U (2006) Practical forecasting procedure for rail traffic impacts. Final report for the research project BMBF 19U0039B, BAM, Berlin (in German)

3. Kuppelwieser H, Ziegler A (1996) A tool for predicting vibration and structure borne noise immissions caused by railways. J Sound Vib 193(1):261-267

4. Madshus C, Bessason B, Harvik L (1996) Prediction model for low frequency vibration from high speed railways on soft ground. J Sound Vib 193(1):195-203

5. With C, Bahrekazemi M, Bodare A (2006) Validation of an empirical model for prediction of train-induced ground vibrations. Soil Dyn Earthq Eng 26(11):983-990

6. Alcover IF, Gjelstrup H, Andersen J et al (2015) Probabilistic empirical model for train-induced vibrations. ICE Proc Struct Build 169(8):563-573

7. Nelson J, Saurenman H (1987) A prediction procedure for rail transportation groundborne noise and vibration. Transp Res Rec 1143:26-35

8. Girardi L (1981) Vibration propagation in homogeneous or laminated soil. In: Annals of the Technical Institute of Building and Public Works, vol 397 (in French)

9. Jones C, Block J (1996) Prediction of ground vibration from freight trains. J Sound Vib 193(1):205-213

10. Rücker W (1982) Dynamic interaction of a railroad-bed with the subsoil. In: Proceedings of soil dynamics and earthquake engineering conference, Southampton, pp 435-448

11. Kausel E, Roesset J (1981) Stiffness matrices for layered soils. Bull Seismol Soc Am 71(6):1743-1761

12. Wolf J (1985) Dynamic soil-structure interaction. Prentice-Hall, Englewood Cliffs

13. Auersch L (1994) Wave propagation in layered soil: theoretical solution in wavenumber domain and experimental results of hammer and railway traffic excitation. J Sound Vib 173(2):233-264

14. Maldonado M (2008) Vibrations due to the passage of a tramexperimental measurements and numerical simulations. $\mathrm{PhD}$ Thesis, Central School of Nantes (in French)

15. Lombaert G, Degrande G (2009) Ground-borne vibration due to static and dynamic axle loads of InterCity and high-speed trains. J Sound Vib 319(3-5):1036-1066

16. Auersch L (2017) Static and dynamic behaviours of isolated and un-isolated ballast tracks using a fast wavenumber domain method. Arch Appl Mech 87(3):555-574

17. Ju S (2007) Finite element analysis of structure borne vibration from high-speed train. Soil Dyn Earthq Eng 27(3):259-273

18. Kouroussis G (2009) Modelling the vibrational effects of rail traffic on the environment, $\mathrm{PhD}$ thesis, University of Mons (in French)

19. Connolly D (2013) Ground borne vibrations from high-speed trains. Dissertation, University of Edinburgh 
20. Auersch L (2005) Dynamics of the railway track and the underlying soil: the boundary-element solution, theoretical results and their experimental verification. Veh Syst Dyn 43(9):671-695

21. Romero A (2012) Prediction, test measures and evaluation of railway traffic vibration. $\mathrm{PhD}$ Thesis, University of Sevilla (in Spanish)

22. Takemiya H, Goda K (1997) Prediction of ground vibration induced by high-speed train operation. In: Proceedings of fifth international congress on sound and vibration (ICSV), Adelaide, Australia

23. Hung H, Yang Y (2001) A review of researches on ground borne vibrations with emphasis on those induced by trains. In: Proceedings of the National Science Councel ROC(A), vol 25, pp 1-16

24. Sheng X, Jones C, Thompson D (2006) Prediction of ground vibration from trains using the wavenumber finite and boundary element methods. J Sound Vib 293(3-5):575-586

25. Galvin P, Francois S, Schevenels M et al (2010) A 2.5D coupled FE-BE model for the prediction of railway induced vibrations. Soil Dyn Earthq Eng 30(12):1500-1512

26. Amado-Mendes P, Alves CP, Godinho L et al (2015) 2.5 D MFSFEM model for the prediction of vibrations due to underground railway traffic. Eng Struct 104:141-154

27. Connolly D, Kouroussis G, Woodward P et al (2014) Scoping prediction of re-radiated ground-borne noise and vibration near high speed rail lines with variable soils. Soil Dyn Earthq Eng 66:78-88

28. Galvin P, Lopez-Mendoza D, Connolly D et al (2018) Scoping assessment of free-field vibrations due to railway traffic. Soil Dyn Earthq Eng 114:598-614

29. Paneiro G, Durão FO, Silva M et al (2018) Artificial neural network model for ground vibration amplitudes prediction due to light railway traffic in urban areas. Neural Comput Appl 29(11):1045-1057

30. Fang L, Yao J, Xia H (2019) Prediction on soil-ground vibration induced by high speed moving train based on artificial neural network model. Adv Mech Eng 11(5):1-10

31. Yao J, Xia H, Zhang $\mathrm{N}$ et al (2014) Prediction on building vibration induced by moving train based on support vector machine and wavelet analysis. J Mech Sci Technol 28(6):2065-2074

32. López-Mendoza D, Romero A, Connolly D et al (2017) Scoping assessment of building vibration induced by railway traffic. Soil Dyn Earthq Eng 93:147-161

33. Lurcock D, Thompson D (2017) A new empirical prediction approach for ground borne vibration in buildings. In: Proceedings of the international congress on sound and vibration, London

34. Cryer D (1994) Modelling of vibration in buildings with application to base isolation. $\mathrm{PhD}$ thesis, University of Cambridge

35. Hunt H (1995) Prediction of vibration transmission from railways into buildings using models of infinite length. Veh Syst Dyn 24:234-247

36. Sanitate G, Talbot J (2016) A power-flow based investigation into the response of tall buildings to ground-borne vibration. In: Proceeding of the international congress on sound and vibration, Athens, pp 1-8

37. Chesnais C (2010) Dynamique de milieux réticulés non contreventés: application aux bâtiments. $\mathrm{PhD}$ thesis, École Centrale de Lyon

38. Zou C, Moore J, Sanayei M et al (2018) Impedance model for estimating train-induced building vibrations. Eng Struct 172:739-750

39. Clot A, Arcos R, Romeu J (2017) Efficient three-dimensional building-soil model for the prediction of ground-borne vibrations in buildings. J Struct Eng 143(9):04017098

40. Villot M, Ropars P, Jean P (2011) Modeling a building response to railway vibration using a source-receiver approach. In: De
Roeck $\mathrm{G}$ et al (ed) Proceedings of the 8th international conference on structural dynamics, EURODYN, pp 671-675

41. Lopes P, Alves Costa P, Ferraz M et al (2014) Numerical modeling of vibrations induced by railway traffic in tunnels: from the source to the nearby buildings. Soil Dyn Earthq Eng 61-62:269-285

42. Hussein M, Hunt H, Kuo K et al (2015) The use of sub-modelling technique to calculate vibration in buildings from underground railways. J. Rail Rapid Transit 229(3):303-314

43. Van den Broeck P (2001) A prediction model for ground-borne vibrations due to railway traffic. $\mathrm{PhD}$ thesis, KU Leuven

44. Triepaichajonsak N (2012) The influence of various excitation mechanisms on ground vibration from trains. $\mathrm{PhD}$ thesis, University of Southampton

45. Alves Costa P (2011) Vibrations of the mass transit system: numerical modelling and experimental validation. PhD thesis, University of Porto (in Portuguese)

46. Yokoyama H, Izumi Y, Watanabe T (2016) A numerical simulation method for ground and building vibration based on three dimensional dynamic analysis. Q Rep Railw Tech Res Inst 57(2):151-157

47. Lombaert G, Degrande G, François S et al (2015) Ground-borne vibration due to railway traffic: a review of excitation mechanisms, prediction methods and mitigation measures. In: Notes on numerical fluid mechanics and multidisciplinary design, Springer, Berlin, pp 253-288

48. Connolly D, Kouroussis G, Laghrouche O et al (2015) Benchmarking railway vibrations: track, vehicle, ground and building effects. Constr Build Mater 92:64-81

49. Thompson D, Kouroussis G, Ntotsios E (2019) Modelling, simulation and evaluation of ground vibration caused by rail vehicles. Veh Syst Dyn 57(7):936-983

50. Auersch L (2010) Theoretical and experimental excitation force spectra for railway induced ground vibration: vehicle-track soil interaction, irregularities and soil measurements. Veh Syst Dyn 48(2):235-261

51. Auersch L (2009) Vehicle dynamics and dynamic excitation forces of railway induced ground vibration. In: Proceedings of the 21 st international symposium on dynamics of vehicles on roads and tracks, KTH Stockholm (CD-ROM), pp 1-12

52. Auersch L (2006) 2- and 3-dimensional methods for the assessment of ballast mats, ballast plates and other isolators of railway vibration. Int J Acoust Vib 11(4):167-176

53. Auersch L, Said S, Müller R (2017) Measurements on the vehicle-track interaction and the excitation of railway-induced ground vibration. Procedia Eng 199:2615-2620

54. Auersch L (2005) The excitation of ground vibration by rail traffic: theory of vehicle-track-soil interaction and measurements on high-speed lines. J Sound Vib 284(1-2):103-132

55. Auersch L, Said S (2015) Comparison of different dispersion evaluation methods and a case history with the inversion to a soil model, related admittance functions, and the prediction of train induced ground vibration. J Near Surf Geophys 13:127-142

56. Auersch L (2008) Dynamic stiffness of foundations on inhomogeneous soils for a realistic prediction of the vertical building resonance. J Geotech Geoenviron Eng 134(3):328-340

57. Auersch L (2010) Building response due to ground vibration simple prediction model based on experience with detailed models and measurements. Int J Acoust Vibr 15(3):101-112

58. Auersch L, Ziemens S (2020) The response of different buildings to free-field excitation: a study using detailed finite element models. In: Papadrakakis M, Fragiadakis M, Papadimitriou C (eds) EURODYN $2020 \mathrm{XI}$ international conference on structural dynamics, Athens

59. Auersch L, Said S, Schmid W et al (2004) Vibrations in construction: measurement results on different buildings and a simple calculation of foundation, wall and ceiling vibrations. Bauingenieur 79:185-192 (in German) 